Research Article

\title{
Evaluation of CMIP5 Global Climate Models over the Volta Basin: Precipitation
}

\author{
Jacob Agyekum (D), ${ }^{1}$ Thompson Annor (i), ${ }^{1}$ Benjamin Lamptey, ${ }^{2}$ Emmannuel Quansah (iD, ${ }^{1}$ \\ and Richard Yao Kuma Agyeman ${ }^{3}$
}

${ }^{1}$ Department of Physics, Kwame Nkrumah University of Science and Technology (KNUST), Kumasi, Ghana

${ }^{2}$ African Centre of Meteorological Applications for Development (ACMAD), Niamey, Niger

${ }^{3}$ Numerical Weather Prediction Unit, Ghana Meteorological Agency (GMet), Accra, Ghana

Correspondence should be addressed to Jacob Agyekum; jacoblyff@gmail.com

Received 9 November 2017; Revised 16 May 2018; Accepted 3 June 2018; Published 29 July 2018

Academic Editor: Olivier P. Prat

Copyright (C) 2018 Jacob Agyekum et al. This is an open access article distributed under the Creative Commons Attribution License, which permits unrestricted use, distribution, and reproduction in any medium, provided the original work is properly cited.

\begin{abstract}
A selected number of global climate models (GCMs) from the fifth Coupled Model Intercomparison Project (CMIP5) were evaluated over the Volta Basin for precipitation. Biases in models were computed by taking the differences between the averages over the period (1950-2004) of the models and the observation, normalized by the average of the observed for the annual and seasonal timescales. The Community Earth System Model, version 1-Biogeochemistry (CESM1-BGC), the Community Climate System Model Version 4 (CCSM4), the Max Planck Institute Earth System Model, Medium Range (MPI-ESM-MR), the Norwegian Earth System Model (NorESM1-M), and the multimodel ensemble mean were able to simulate the observed climatological mean of the annual total precipitation well (average biases of $1.9 \%$ to $7.5 \%$ ) and hence were selected for the seasonal and monthly timescales. Overall, all the models (CESM1-BGC, CCSM4, MPI-ESM-MR, and NorESM1-M) scored relatively low for correlation $(<0.5)$ but simulated the observed temporal variability differently ranging from 1.0 to 3.0 for the seasonal total. For the annual cycle of the monthly total, the CESM1-BGC, the MPI-ESM-MR, and the NorESM1-M were able to simulate the peak of the observed rainy season well in the Soudano-Sahel, the Sahel, and the entire basin, respectively, while all the models had difficulty in simulating the bimodal pattern of the Guinea Coast. The ensemble mean shows high performance compared to the individual models in various timescales.
\end{abstract}

\section{Introduction}

Rainfall is an important component of the hydrological cycle and plays an essential role in determining the amount of water available at the surface. Most of the countries in West Africa depend mainly on rainfed agriculture [1], and therefore, the amount of rainfall affects the crop yield [2]. A decrease in the amount of precipitation may lead to drought $[3,4]$, while an increase can cause flooding [5]. In the past years, incidents of floods in West Africa have caused a devastating impact on people's health and destruction to properties and livelihood [6]. The Volta Basin is a major source of water to a number of countries [7] in the West African region. It serves as a major driving force of the economic progress of many countries in West Africa including Ghana, Burkina Faso, Cote d'Ivoire Mali, and Togo $[8,9]$. In Ghana, the major source of energy (hydroelectric power) is generated mainly from the Akosombo Dam, Kpong Dam, and Bui Dam [9]. These dams have been constructed at different locations within the basin and contribute more than $60 \%[9,10]$ of hydroelectric power, to the total energy needs of the country. The Volta Basin can be divided into the Guinea Coast, the Soudano-Sahel, and the Sahel $[11,12]$ agroecological zones (Figure 1), based on the annual amount of precipitation received by these subregions. Therefore, changes in the amount of precipitation and hence changes in the amount of available water affect the lives of the inhabitants [13]. Changes in the future climates 


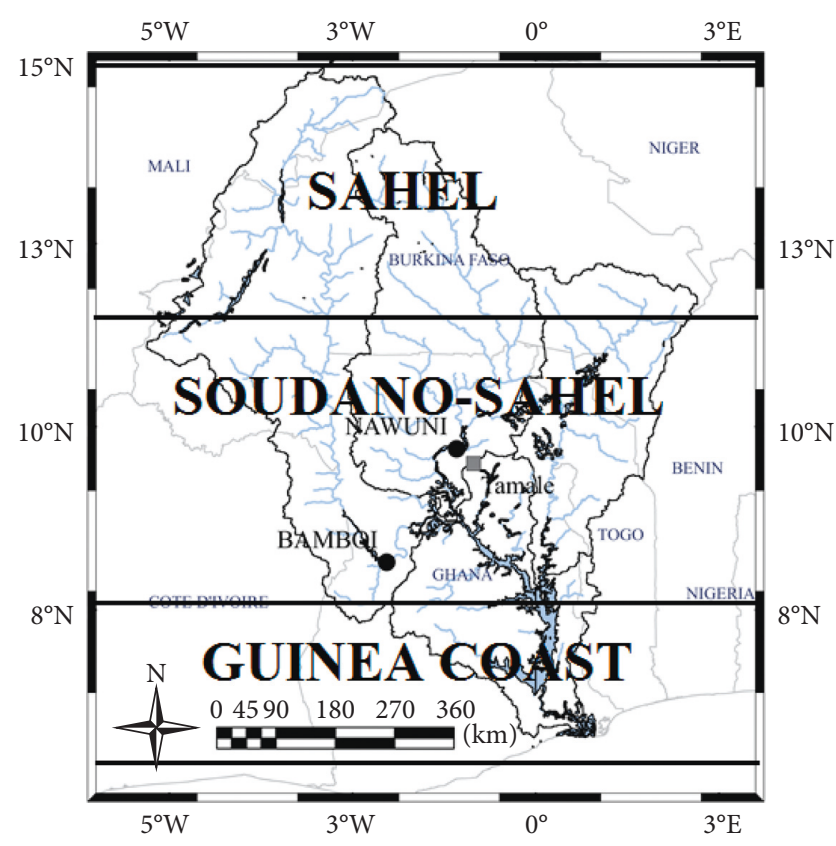

Figure 1: The three ecological zones in the basin, from the humid Guinea Coast to the semiarid Sahel (modified from Fujihara et al. [45]).

of the globe and the West African region imply likely changes in the hydrology and water resources of the Volta Basin which raise serious concerns that demand urgent attention for the region. Various climate studies (that mainly apply GCMs) on the future of the earth's climate system suggest changes in the climate from global (e.g., [14-16]) to the regional scales (e.g., $[17,18])$.

Also, a regional climate model (RCM) takes its input from a GCM, and therefore, the performance of the driving GCM is a crucial issue that should not be ignored. In essence of that, forcing data from a poorly performed GCM can significantly affect the performances of the RCM. It is therefore important to assess the performances of GCMs over an economically important basin such as the Volta.

Mehran et al. [19] evaluated 34 CMIP5 GCMs in reproducing observed precipitation over the globe using the volumetric hit index (VHI) analysis. In their study, the GCMs showed good agreement with the observed, but reproducing the observed precipitation over arid regions and certain subcontinental regions was problematic, for the total monthly precipitation. This confirms the assertion that GCMs have limitations when it comes to the representation of observed precipitation on both short temporal and small spatial scales (e.g., [18]). They also indicated the superior performance of the multimodel ensemble mean to the individual models. Kumar et al. [20] have also evaluated temperature and precipitation trends in 19 CMIP5 GCMs, focusing on continental areas $\left(60^{\circ} \mathrm{S}-60^{\circ} \mathrm{N}\right)$ for the $1930-2004$ period. They showed that there are large uncertainties in the models in simulating local-scale temperature and precipitation trends. They also indicated the high performance of the multimodel ensemble average compared to the individual models. Other studies have evaluated the performance of CMIP5 models over other regions including North
Pacific [21], Europe [22-24], and Asia (e.g., [25-28]) and reported high variations in the performances of the GCMs over the different regions.

Over Africa, Nikulin et al. [29] evaluated the performance of CORDEX-RCMs in simulating precipitation. They evaluated the simulated precipitation at seasonal, annual, and diurnal timescales and indicated that all models simulated the seasonal and annual precipitation quite well. They also indicated the superior performance of the ensemble average of the RCMs to the individual models. Nikiema et al. [30] reported better multimodel CMIP5 and CORDEX simulations of historical summer temperature and precipitation variabilities over West Africa. They evaluated and intercompared the multimodel ensembles of the CMIP5 and the CORDEX and found that while CORDEX failed to outperform the simulated mean climatology of temperature by the CMIP5 ensembles, it substantially improved the simulation of precipitation and provided a more realistic fine-scale features tied to local topography and land use. Over the Volta Basin, Annor et al. [31] evaluated the performance of the Weather Research and Forecast (WRF) model forced by the MPI-ESM-MR in reproducing the present day (1980-2005) temperature and precipitation. They reported the transfer of bias from the GCM to the RCM and indicated that, at certain instances, the RCM minimized the bias and at other instances increased the GCM bias in both temperature and precipitation. Agyeman et al. [32] assessed the best physics parameterization scheme combination for seasonal simulation over Ghana and showed that scheme combinations are sensitive to the agroclimatic belts within the country. Aziz and Obuobie [33] looked at trend analysis in observed (1981-2010) and projected (2051-2075 and 2076-2100 under the IPCC Representative Concentration Pathways RCP4.5 and RCP8.5) precipitation and mean temperature over the Black Volta Basin using RCMs. They showed a statistically significant (at the $5 \%$ significant level) increase of $111 \mathrm{~mm}$ in the annual rainfall, whereas a significant increase of $0.9^{\circ} \mathrm{C}$ in temperature for the observed period. For the future projection, there is high uncertainty in the trend of rainfall (which is statistically nonsignificant), as some ensemble members project positive trends, while others gave negative trends. With regard to the temperature, average annual projection showed increases over the basin, with the warming being higher under the RCP8.5 scenario than under the RCP4.5 scenario.

The above studies have contributed immensely to the assessment of the performance of GCMs and RCMs in reproducing the observed climatology of various regions including Africa, but very few focus on the Volta Basin and the very few that targeted the basin in most cases assessed single GCMs. Therefore, assessing the performances of several GCMs from the CMIP5 over the Volta Basin will contribute significantly to the efforts in climate modeling over the region. Giorgi and Gutowski [34] indicated the importance of analyzing the performance of GCMs before they are used to drive RCMs. This study therefore focuses on the performance of 18 GCMs in simulating precipitation over the Volta Basin and the three belts (Guinea Coast, Soudano-Sahel, and Sahel). 
In this paper, the performance of GCMs in simulating observed precipitation is presented. Section 2 presents the observational data and the models used for the study including the methods used for the evaluation of models. Section 3 discusses the results. The summary and conclusions are found in Section 4.

\section{Materials and Methods}

\subsection{Data}

2.1.1. Observational Data. In this study, the Global Precipitation Climatology Centre (GPCC) version seven (v7) precipitation data [35] on a $0.5^{\circ} \times 0.5^{\circ}$ grid resolution is used as reference precipitation data that depict spatial variability over the basin. This data set comprises observations based on three-dimensional variational assimilation [36]. Due to the highly varying spatial distribution of precipitation, spatial density of observed precipitation data is crucial over West Africa. Studies (e.g., [37, 38]) have indicated that the availability of high-quality data set especially in the case of precipitation over West Africa is problematic. Consequently, gridded observational open-source data sets become the practical option for model validation purposes within the region. The selection of the GPCC data as reference data for this evaluation study is based on the fact that they have been applied in similar model evaluation studies (e.g., [31, 32]) over the West African region. Other studies including Gruber et al. [39], Nicholson et al. [37], Paeth et al. [38], and Nikulin et al. [29] have demonstrated the robustness of GPCC data in reproducing observed precipitation in the West African region. These studies expressed confidence in this particular data set. Moreover, there are a significant number of gauge stations over West Africa that have been incorporated in the development of the GPCC data set. However, the GPCC data have low gauge station density over the Sahara region [29].

2.1.2. Model Data. All the model outputs evaluated in this study are from the CMIP5, used in the preparation of the Fifth Assessment Report (AR5) of the Intergovernmental Panel on Climate Change (IPCC). This is the latest phase of a coordinated effort by modeling groups across the globe to systematically perform so many prescribed climate model experiments [40]. The study uses 18 GCM simulations provided by 16 modeling centres and groups. The model names, acronyms, and their horizontal and vertical resolutions are shown in Table 1. The selection of these GCMs are based on the fact that most of the GCMs have been applied extensively over the basin (e.g., $[18,31]$ ), and also our selection was informed by the availability of model data with similar ensemble members. Although these are not the only models with similar ensemble members, all the ones we used are of similar ensemble members for the present. All the models are long-term historical runs from the CMIP5 experiments which include a preindustrial control (piControl) experiments. They all include the same ensemble member (rlilp1); that is, all the models are initialized from the same initial observed conditions (initialization 1 (i1)), the same methods (realization 1 (r1)), and the same "perturbed physics" 1 (p1) [41]. For each model, total monthly precipitation data of 55 years (1950-2004) were used for the study. The Program for Climate Model Diagnosis and Intercomparison (PCMDI) collected the model data as part of the process leading to the CMIP5 [42].

2.2. Methods. The models' performances in reproducing the observed climatology are analyzed relative to the observational data. First, each of the model grids was bilinearly interpolated $[43,44]$ to the GPCC grid of $0.5^{\circ} \times 0.5^{\circ}$ resolution to facilitate direct comparison of the models with the observational data. The comparison was done over the Volta Basin $\left(4.9^{\circ} \mathrm{N}-16^{\circ} \mathrm{N} ; 6^{\circ} \mathrm{W}-3^{\circ} \mathrm{E}\right)$ and the three subregions including the Guinea Coast $\left(4.9^{\circ} \mathrm{N}-8^{\circ} \mathrm{N}\right)$, the Soudano-Sahel $\left(8^{\circ} \mathrm{N}-\right.$ $\left.12^{\circ} \mathrm{N}\right)$, and the Sahel $\left(12^{\circ} \mathrm{N}-16^{\circ} \mathrm{N}\right)$ [12], for the annual, seasonal, and monthly timescales. The Guinea Coast (GC) is characterized by a bimodal pattern of precipitation (a maximum peak in June and a second one in September), while the Soudano-Sahel (SD) and the Sahel (SA) regions are characterized by a unimodal pattern (the maximum peak in August in both cases). These modes are influenced by the meridional movements of the ITCZ within the year. Figure 1 shows a map of the Volta Basin including the three subregions.

2.2.1. Annual Scale Analysis. On the annual scale, biases in models were computed by taking the differences between the averages over the period (1950-2004) of the models and the observation, normalized by the average of the observed as shown in (1).

This is done to assess the spatial biases in the models over the entire basin for the study period (1950-2004):

$$
\text { Relative bias }=\frac{\text { model }- \text { observed }}{\text { observed }} \times 100 \% \text {. }
$$

2.2.2. Seasonal Scale Analysis. In the seasonal total, biases in the models were computed in the same manner done for the annual totals using (1). This is done for the dry (November, December, January, February, and March (NDJFM)) and rainy (April, May, June, July, August, September, and October (AMJJASO)) seasons of the Volta Basin. Secondly, the three statistics, the standardized deviation $(\sigma)(2)$, the correlation coefficient $(r)$ (3), and the root-mean-square error (RMSE) (4) were computed, representing the temporal variability, the temporal pattern, and the temporal errors in the models, respectively. This is done for the DJF, MAM, JJA, and SON standard seasons for the entire basin and the three belts. Lastly, trend analysis was done over the Volta Basin and the three belts for the various seasons that are found over these regions. The standard deviation $(\sigma)$ is given by

$$
\sigma=\sqrt{\frac{1}{N} \sum_{i=1}^{N}\left(x_{i}-\bar{x}\right)^{2}},
$$

where $N$ is the total number of data points and $\bar{x}$ is the mean of the individual data points, $x_{i}$. 
TABLE 1: Details of models used in the study (the descriptions are from Taylor et al. [42]), showing models' spatial resolution for the Atmospheric Global Climate Model (AGCM) and Oceanic Global Climate Model (OGCM) and the various institutions that produced the models.

\begin{tabular}{|c|c|c|}
\hline Model name & $\begin{array}{l}\text { Resolution, number of grids (lon. } \times \text { lat.; levels) } \\
\text { of AGCM (OGCM) }\end{array}$ & Institution \\
\hline BCC-CSM1.1 & $128 \times 64 ; 26(360 \times 232 ; 40)$ & $\begin{array}{c}\text { Beijing Climate Center, China Meteorological } \\
\text { Administration, China }\end{array}$ \\
\hline BNU-ESM & $128 \times 64 ; 26(360 \times 200 ; 50)$ & $\begin{array}{c}\text { College of Global Change and Earth System Science, } \\
\text { Beijing Normal University }\end{array}$ \\
\hline CanESM2 & $128 \times 64 ; 26(360 \times 192 ; 40)$ & $\begin{array}{c}\text { Canadian Centre for Climate Modelling and } \\
\text { Analysis, Canada }\end{array}$ \\
\hline CCSM4 & $228 \times 192 ; 26(320 \times 384 ; 60)$ & National Center for Atmospheric Research, USA \\
\hline CESM1-BGC & $288 \times 192 ; 26$ & National Center for Atmospheric Research, USA \\
\hline CMCC-CM & $480 \times 240 ; 31(182 \times 149 ; 31)$ & $\begin{array}{c}\text { Centro Euro-Mediterraneo per I Cambiamenti } \\
\text { Climatici, Italy }\end{array}$ \\
\hline CNRM-CM5 & $256 \times 128 ; 31(362 \times 292 ; 42)$ & $\begin{array}{l}\text { Centre National de Rescherches } \\
\text { Meteorologiques/Centre Europeen de Recherche et } \\
\text { Formation Avances en Calcu Scientifique, France } \\
\text { Commonwealth Scientific and Industrial Research }\end{array}$ \\
\hline CSIRO-Mk3.6.0 & $192 \times 96 ; 18(192 \times 189 ; 31)$ & $\begin{array}{l}\text { Organisation in collaboration with the Queensland } \\
\text { Climate Change Centre of Excellence, Australia }\end{array}$ \\
\hline EC-EARTH & $320 \times 160 ; 21(182 \times 149 ; 31)$ & EC-Earth (European Earth System Model) \\
\hline HadGEM2-AO & $192 \times 145 ; 60(360 \times 216 ; 40)$ & $\begin{array}{c}\text { National Institute of Meteorological Research, Seoul, } \\
\text { South Korea }\end{array}$ \\
\hline HadGEM2-CC & $192 \times 144 ; 60(360 \times 216 ; 40)$ & Met Office Hadley Centre, UK \\
\hline INMCM4 & $180 \times 120 ; 21(360 \times 340 ; 40)$ & Institute of Numerical Mathematics, Russia \\
\hline IPSL-CM5A-MR & $96 \times 96 ; 39(182 \times 149 ; 31)$ & $\begin{array}{l}\text { Institut Pierre Simon Laplace, France } \\
\text { Atmosphere and Ocean Research Institute (The }\end{array}$ \\
\hline MIROC5 & $256 \times 128 ; 40(256 \times 224 ; 50)$ & $\begin{array}{l}\text { University of Tokyo), National Institute for } \\
\text { Environmental Studies, and Japan Agency for } \\
\text { Marine-Earth Science and Technology, Japan } \\
\text { Japan Agency for Marine-Earth Science and }\end{array}$ \\
\hline MIROC-ESM & $128 \times 64 ; 80(256 \times 192 ; 44)$ & $\begin{array}{l}\text { Technology, Atmosphere and Ocean Research } \\
\text { Institute (The University of Tokyo), and National } \\
\text { Institute for Environmental Studies, Japan }\end{array}$ \\
\hline MPI-ESM-MR & $192 \times 96 ; 47(256 \times 220 ; 40)$ & $\begin{array}{l}\text { Max Planck Institute for Meteorology (MPI-M), } \\
\text { Germany }\end{array}$ \\
\hline MRI-CGCM3 & $320 \times 160 ; 48(360 \times 368 ; 51)$ & Meteorological Research Institute, Japan \\
\hline NorESM1-M & $144 \times 96 ; 26(320 \times 384 ; 70)$ & Norwegian Climate Centre, Norway \\
\hline
\end{tabular}

The correlation coefficient $r$ between the variables $x$ and $y$ is defined as follows:

$$
r=\frac{(1 / N) \sum_{i=1}^{N}\left(x_{n}-\bar{x}\right)\left(y_{n}-\bar{y}\right)}{\sigma_{x} \sigma_{y}} .
$$

The root-mean-square error (RMSE) for the fields $f$ and $r$ is defined as follows:

$$
\text { RMSE }=\left[\frac{1}{N} \sum_{i=1}^{N}\left(f_{i}-r_{i}\right)^{2}\right]^{1 / 2} .
$$

The trends in the seasonal precipitation over the entire basin and the three zones are also considered using the Mann-Kendall (MK) test [46, 47]. Pettitt's test [48] was used for the change-point detection. The Theil-Sen estimator [49] was applied in the case of the slope. The MK test is a nonparametric rank-based statistical test used for detecting monotonic trends in time-series data. In comparison with other nonparametric procedures, such as
Spearman's rho test [50], the power of the Mann-Kendal test is robust and similar to the extent of giving indistinguishable results in practice [51]. The MK statistic $\left(S_{\mathrm{mk}}\right)$ is calculated theoretically using the following equation:

$$
S_{\mathrm{mk}}=\sum_{i=1}^{N} \sum_{j=i+1}^{N} \operatorname{sgn}\left(X_{j}-X_{i}\right),
$$

where $X_{j}$ and $X_{i}$ are the data values of $j$ and $i$, such that $(j>i)$, and sgn is given as follows:

$$
\begin{array}{ll}
\operatorname{sgn}\left(X_{j}-X_{i}\right)=0 & \text { if } X_{j}-X_{i}=0, \\
\operatorname{sgn}\left(X_{j}-X_{i}\right)=1 & \text { if } X_{j}-X_{i}>0, \\
\operatorname{sgn}\left(X_{j}-X_{i}\right)=-1 & \text { if } X_{j}-X_{i}<0 .
\end{array}
$$

Under the null hypothesis of no trend and independence of the series terms, the variance of the Mann-Kendall statistic is calculated as follows: 


$$
\operatorname{var}\left(S_{\mathrm{mk}}\right)=\frac{N(N-1)(2 N+5)-\sum_{i=1}^{M} U_{i}(i)(i-1)(2 i+5)}{18},
$$

where $M$ is the number of tied groups and $U_{i}$ represents the size of the $M$ th group. The summation term in the numerator is used only if the data series contains tied values. For the sample size $n \geq 10$, the statistic $S$ assumes normal distribution, and the standard normal test statistic $Z_{\mathrm{S}}$ is computed as follows:

$$
\begin{aligned}
& Z_{\mathrm{S}}=0 \quad \text { for } S=0, \\
& Z_{\mathrm{S}}=\frac{S-1}{\sqrt{\operatorname{var}(S)}} \quad \text { for } S>0, \\
& Z_{\mathrm{S}}=\frac{S+1}{\sqrt{\operatorname{var}(S)}} \quad \text { for } S<0 .
\end{aligned}
$$

And for the $p$ values for the MK test,

$$
p=0.5-\varphi\left(\left|Z_{\mathrm{S}}\right|\right) \text {. }
$$

The trend results in this study have been evaluated at the $5 \%$ significant level (95\% confidence level). The corresponding threshold $(Z)$ value is \pm 1.96 . This implies that the null hypothesis is rejected when $\left|Z_{S}\right| \geq Z_{\alpha / 2}$ in (8)-(10) at the $\alpha=0.05$ level of significance.

For Pettitt's test, which represents a sudden change in the statistics of a record, (12)-(14) were used:

$$
K_{T}=\max \left|U_{t T}\right|,
$$

where

$$
U_{T}=\sum_{i=1}^{N} \sum_{j=i+1}^{N} \operatorname{sgn}\left(X_{j}-X_{i}\right)
$$

The change point is located at $K_{T}$, provided the statistic $(p<0.05)$ is significant:

$$
p=2 \exp \left(\frac{-6 K_{T}^{2}}{T^{3}+T^{2}}\right)
$$

The magnitude of the trend is estimated using the Theil-Sen estimator which robustly fits a line to sample points in the plane by choosing the median of the slopes of all lines through pairs of points. The estimation is given by

$$
Q_{i}=\frac{X_{j}-X_{k}}{j-k} \quad \text { for all } k<j \text { and } i=1, \ldots, N,
$$

where $Q_{i}=$ slope between the data points $X_{j}$ and $X_{k}$, $X_{j}=$ data values at time $j$, and $X_{k}=$ data values at time $k$. $N=(n(n-1)) / 2$, where $1<k<j<n$ and $n$ is the total number of observations for each period. The $N$ values of $Q_{i}$ are ranked from the least to the largest, and the median of these $N$ values of $Q_{i}$ is Sen's estimate of the slope computed as follows:

$$
Q_{\text {med }}=Q\left[\frac{N+1}{2}\right]
$$

when $N$ is an odd number, and

$$
Q_{\text {med }}=Q\left[\frac{N}{2}\right]+Q\left[\frac{N+2}{2}\right],
$$

when $N$ is an even number.

The direction of the trend is given by the sign of $Q_{\text {med }}$, while its magnitude indicates the steepness of the trend.

2.2.3. Annual Cycle of Monthly Total Precipitation Analysis. In the annual cycle analysis, the climatological monthly mean for all the models for the whole 55-year period was compared to that of the GPCC precipitation data. First, area averages over the whole Volta Basin and the three ecological zones, the Guinea Coast, the Soudano-Sahel, and the Sahel, were computed. This is done to assess the models' ability in reproducing the bimodal pattern of precipitation over the Guinea Coast and the unimodal pattern of precipitation over the Volta Basin, the Soudano-Sahel, and the Sahel.

\section{Results and Discussion}

The performance of the selected CMIP5 GCMs relative to the GPCC precipitation data is presented on the annual, seasonal, and monthly timescales.

3.1. Annual Total for Climatological Mean Bias. The climatological (1950-2004) mean biases in the annual total for the individual models are presented in Figures 2-5. There are overestimation and underestimation of the observed annual precipitation over the basin by some of the models. Some models simulated precipitation close to the observed precipitation over major parts of the basin.

Figure 2 shows the results of models overestimating the observed precipitation over most parts of the basin with wet bias up to $196 \%$. The MIROC5 overestimates the amount of precipitation over the entire basin with the highest mean relative bias of $102.5 \%$. CSIRO-Mk3.6.0 overestimates the Sahelian part of the basin with a maximum relative bias of $116.0 \%$ and underestimates the Guinea Coast with a minimum relative bias of $-42.0 \%$, whereas the MIROC-ESM overestimates mostly the southern part of the basin with a mean relative bias over the whole basin of $23.0 \%$ where the biases are ranging from $-19.0 \%$ to $195.6 \%$. The CanESM2, the CNRM-CM5, and the EC-EARTH overestimate precipitation almost over the entire basin with biases ranging from $-12.3 \%$ to $112.0 \%$. The Volta Basin's precipitation climatology is controlled mainly by the two winds [52]: the northeasterlies, which are characterized by dry cold winds from the Sahara, and the southwesterlies, characterized by moist warm winds from the Atlantic Ocean. A proper representation of these two air masses is relevant for the simulation of the precipitation. Models that overestimate precipitation could exaggerate the effects of the moist winds from the Atlantic Ocean (e.g., [52, 53]).

Figure 3 represents the results of models generally underestimating the observed precipitation over most parts of the basin with bias up to $-114 \%$. The MRI-CGCM3, 


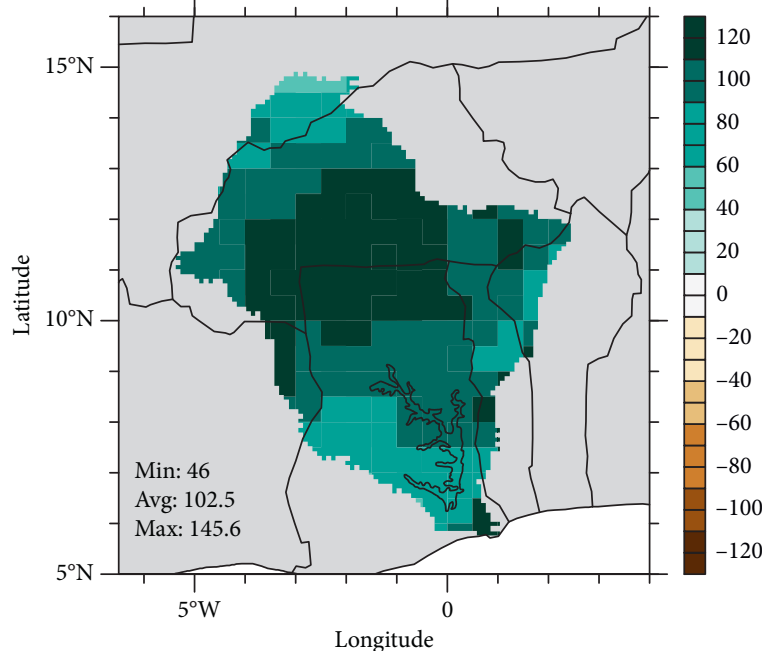

(a)

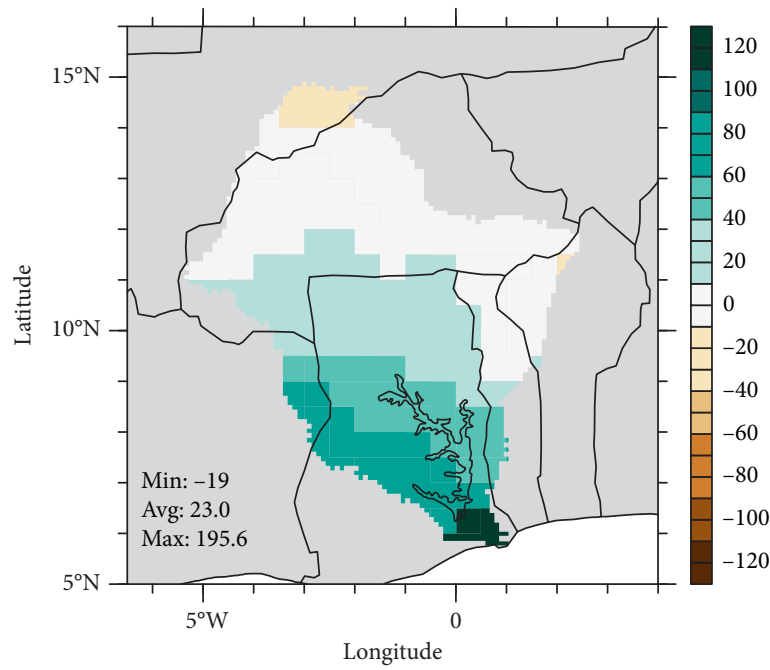

(c)

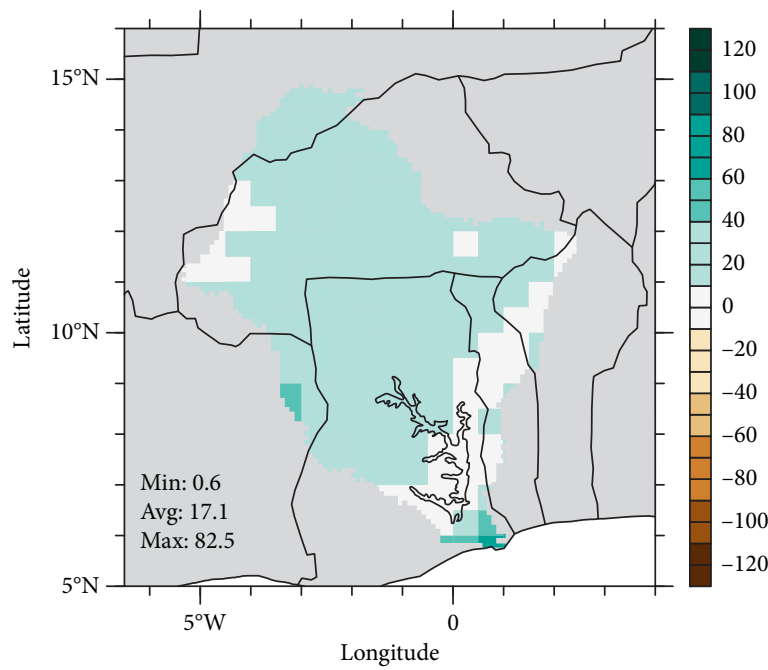

(e)

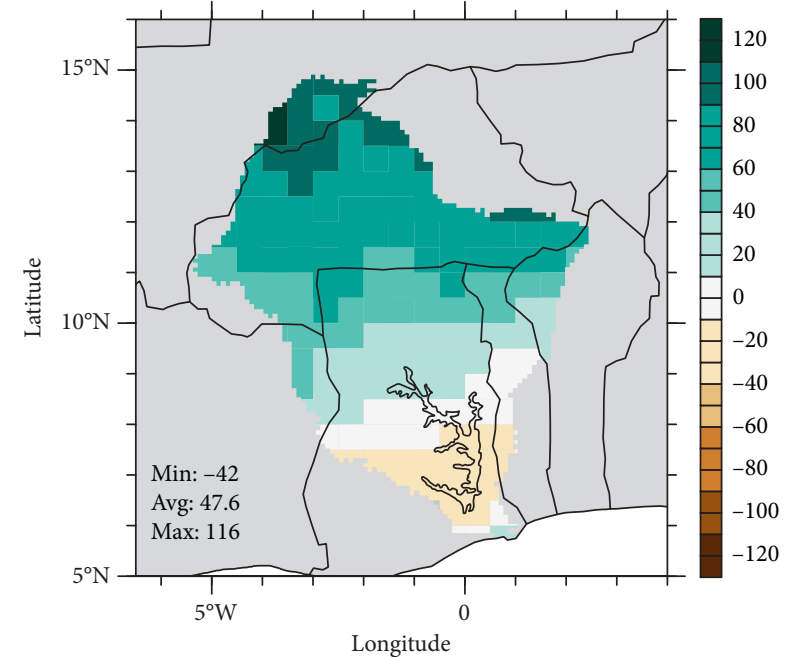

(b)

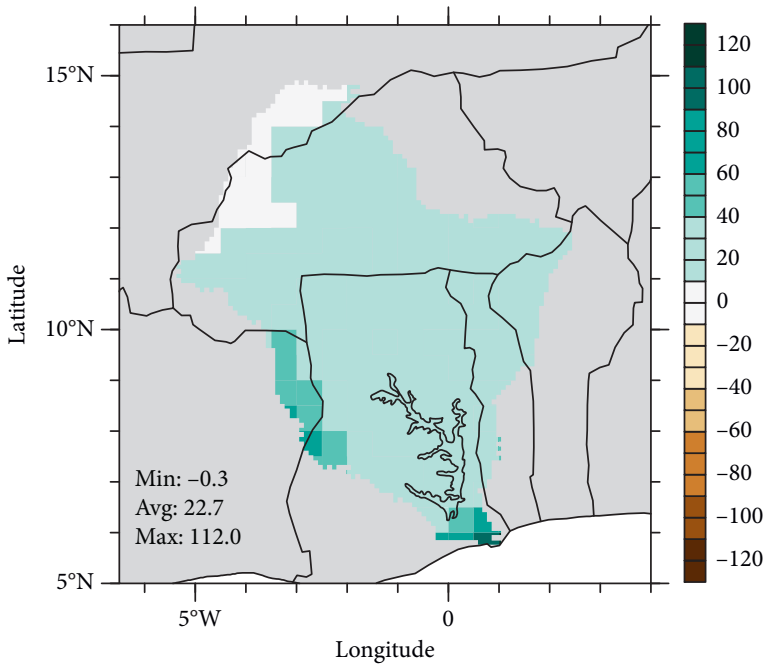

(d)

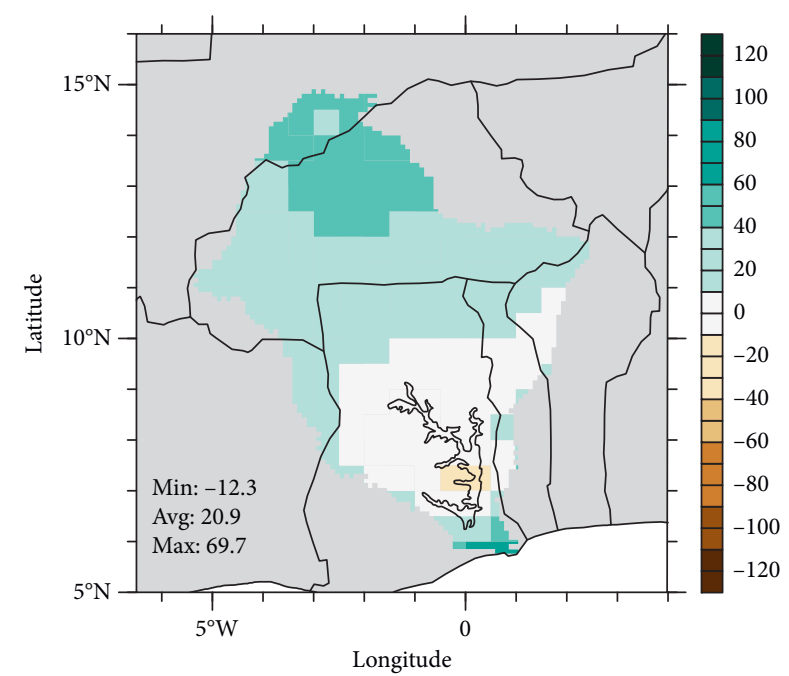

(f)

FIgURE 2: The climatological (1950-2004) mean bias in the annual total precipitation for the models: MIROC5 (a), CSIRO-Mk3.6.0 (b), MIROC-ESM (c), CNRM-CM5 (d), CanESM2 (e), and EC-EARTH (f), overestimating the observed climatological mean over major parts of the Volta Basin. 


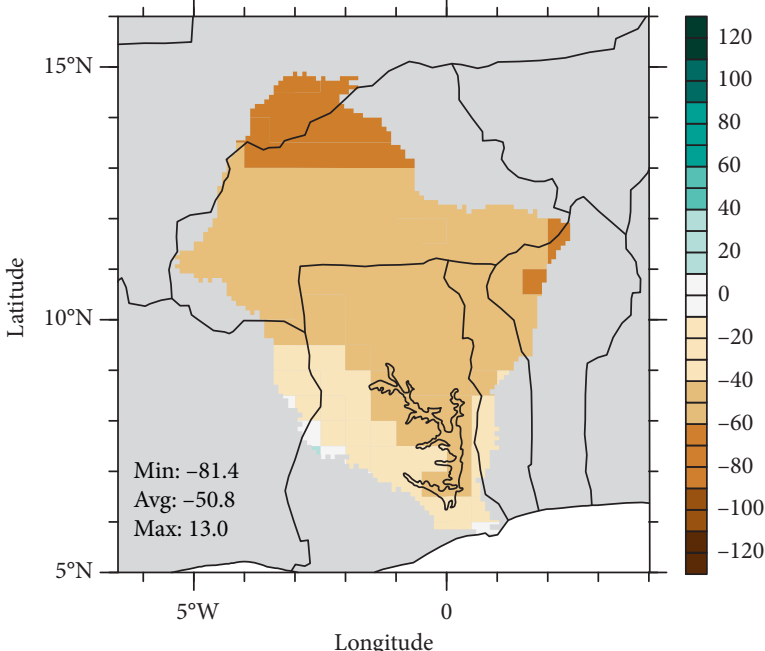

(a)

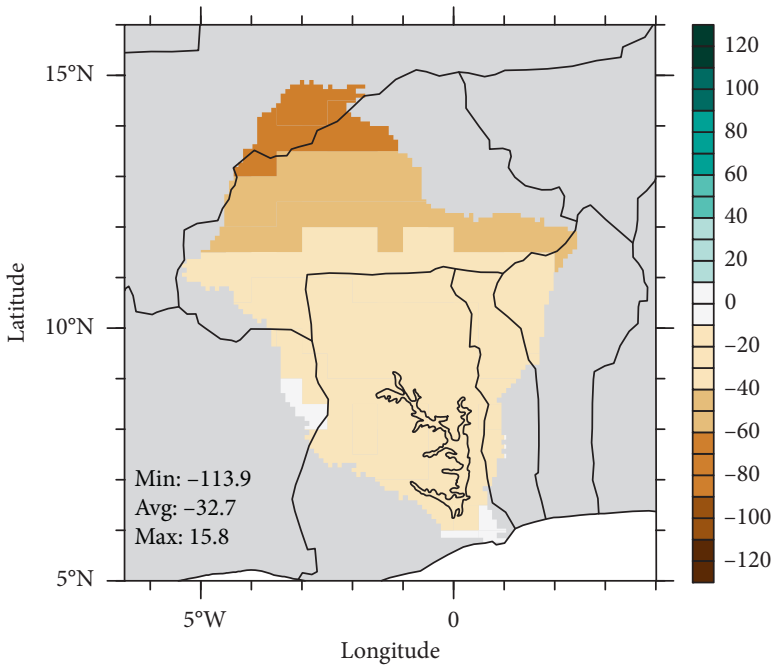

(c)

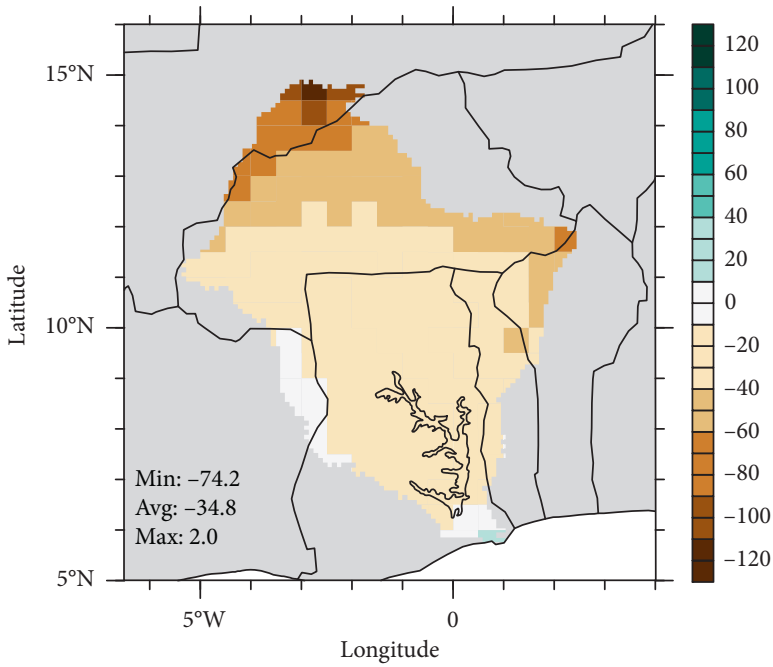

(e)

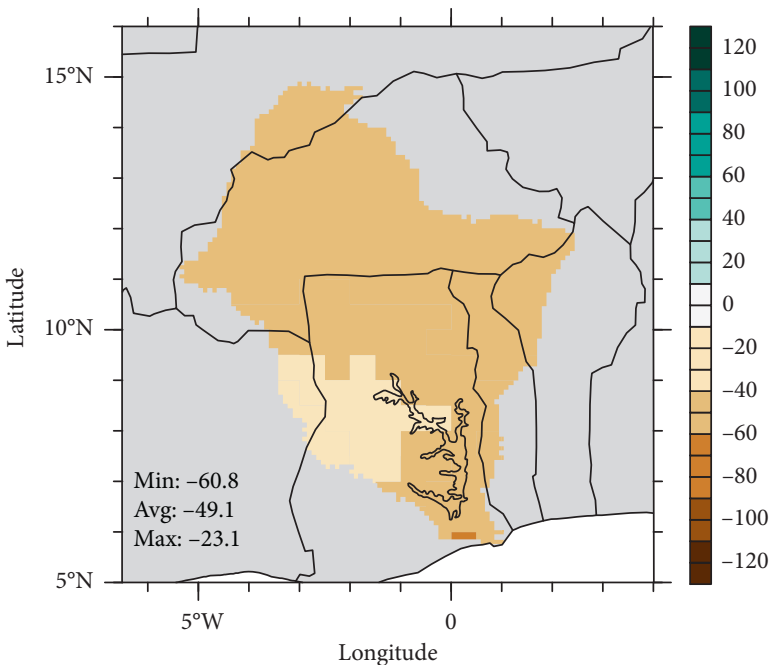

(b)

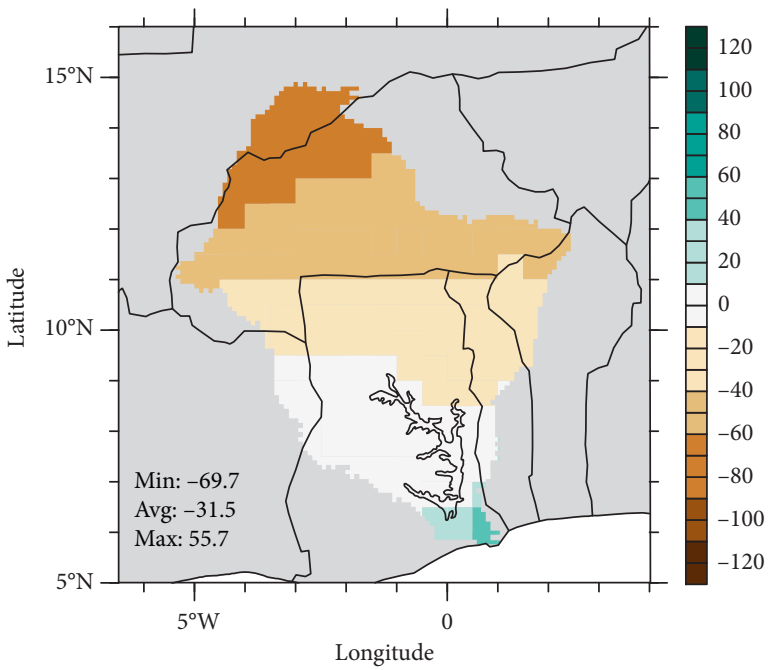

(d)

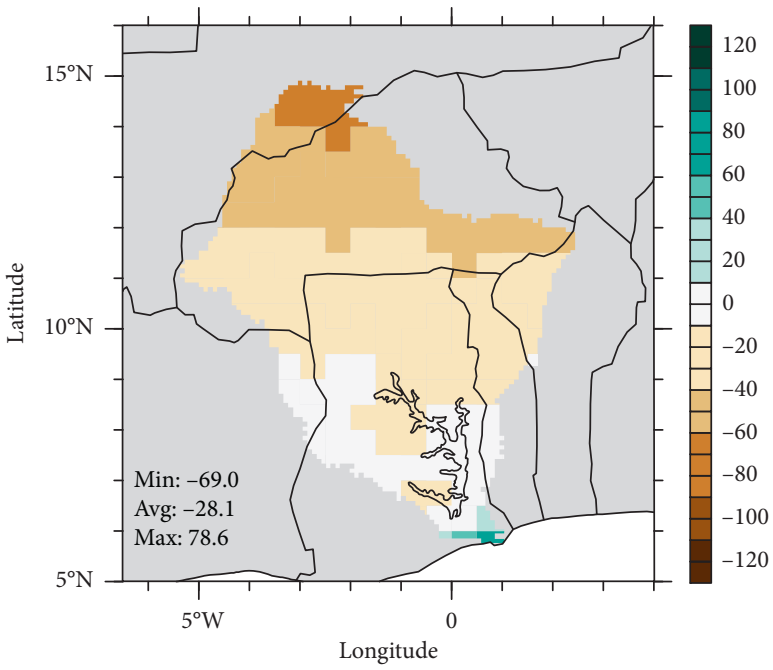

(f)

FIgURE 3: The climatological (1950-2004) mean bias in the annual total precipitation for the models: MRI-CGCM3 (a), INMCM4 (b), HadGEM2-CC (c), IPSL-CM5A-MR (d), HadGEM2-AO (e), and CMCC-CM (f), underestimating the observed climatological mean over major parts of the Volta Basin. 


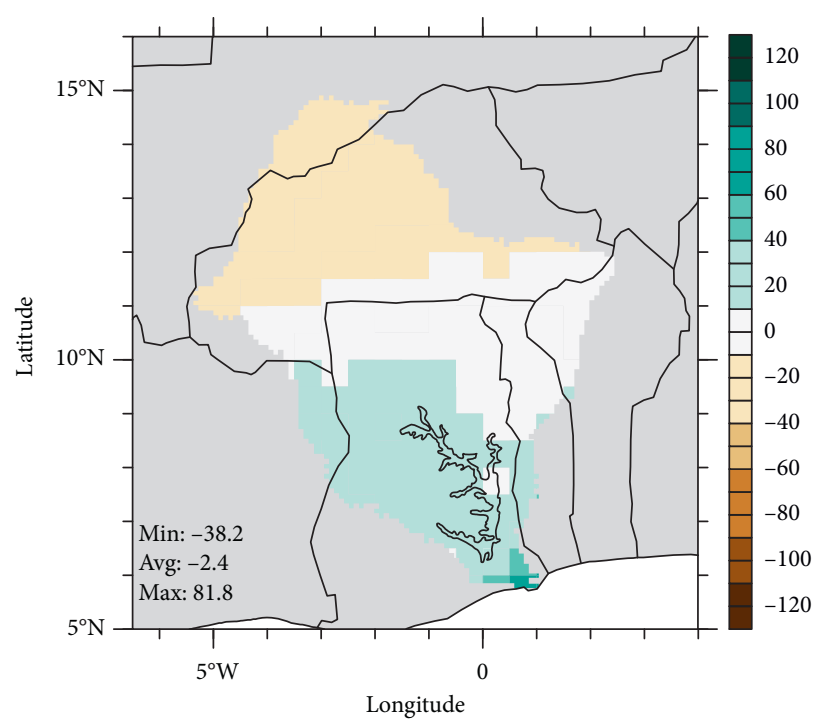

(a)

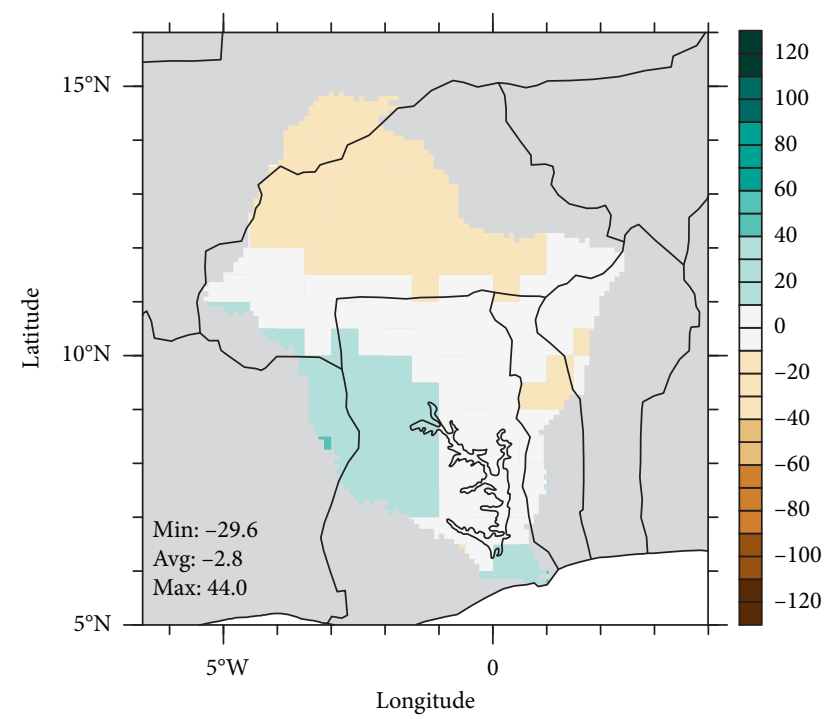

(b)

FIgURE 4: The climatological (1950-2004) mean bias in the annual total precipitation of BCC-CSM1.1 (a) and BNU-ESM (b). They averagely underestimate the observed precipitation.

INMCM4, HadGEM2-CC, IPSL-CM5A-MR, HadGEM2-AO, and CMCC-CM underestimate the observed precipitation and have mean biases of $-50.8 \%,-49.1 \%,-32.7 \%,-31.5 \%,-34.8 \%$, and $-28.1 \%$, respectively. These models could probably exaggerate the effects of the dry winds from the Sahara and also the warming of the troposphere by greenhouse gases that decrease the vertical temperature gradient inducing a stable atmosphere (e.g., $[54,55])$.

Figure 4 shows the Beijing Climate Center Climate System Model version 1.1 (BCC-CSM1.1) and the Beijing Normal University Earth System Model (BNU-ESM) underestimating the observed precipitation in the Sahel while overestimating in the Guinea Coast. Averagely, both models underestimate precipitation over the entire basin.

The CESM1-BGC, CCSM4, NorESM1-M, MPI-ESM-MR, and multimodel ensemble mean are able to simulate precipitation close to the observed precipitation value, with mean biases of $4.6 \%, 7.5 \%, 2.8 \%, 6.1 \%$, and $1.9 \%$, respectively, as shown in Figure 5. These models are able to simulate the observed precipitation relatively well. Due to the ability of these models to simulate the annual climatology over the basin, they are then considered for the seasonal and monthly timescale analyses.

3.2. Seasonal Total for Climatological Mean Bias. The climatological (1950-2004) mean biases in the seasonal totals of the four models with the least annual climatological mean biases are presented in Figures 6 and 7. The two seasons: the dry season (NDJFM) and the rainy season (AMJJASO), are considered over the entire basin.

3.2.1. The Dry Season. This season is characterized by small amount of precipitation over the Volta Basin and coincides with the Northern Hemispheric winter season. Excluding the MPI-ESM-MR which underestimates the observed precipitation (average bias of $-47.5 \%$ ) over the entire basin, all the models including the ensemble mean (EM) of all the 18 models overestimate precipitation over the Sahelian region with biases up to $164.8 \%$, whereas the precipitation over the Guinea Coast and some parts of the Soudano-Sahel is underestimated (up to 34\%), as shown in Figure 6. Averagely, the CESM1-BGC and the NorESM1-M estimate seasonal precipitation close to the observed precipitation with biases of $14.2 \%$ and $7.9 \%$, respectively. Simulating observed climatology for shorter timescales is a major limitation of GCMs [56], as shown in the models' inability to reproduce the observed seasonal precipitation well though these four models and ability to simulate the observed precipitation well in the case of the annual total.

3.2.2. The Rainy Season. This season follows the major dry season with a gradual increase in precipitation which peaks in August. During the rainy season, precipitation varies greatly from one latitude to the other. For this season, as shown in Figure 7, the NorESM1-M and the EM simulate minimal seasonal mean biases of $4.0 \%$ and $4.3 \%$, respectively. All the models, including the EM, overestimate the observed seasonal precipitation over the Guinea Coast and some portions of the Soudano-Sahel. In addition to the GCMs' limitation in simulating shorter timescales for precipitation, their course grids pose a major challenge in simulating subgrid features such as orography, convective clouds, and vegetation [57] which might have impacted significantly on the simulation of the precipitation.

\subsection{Regional Differences in Precipitation}

3.3.1. Annual Cycles of Monthly Total Precipitation. In the annual cycle, as shown in Figure 8, the ability of the models 


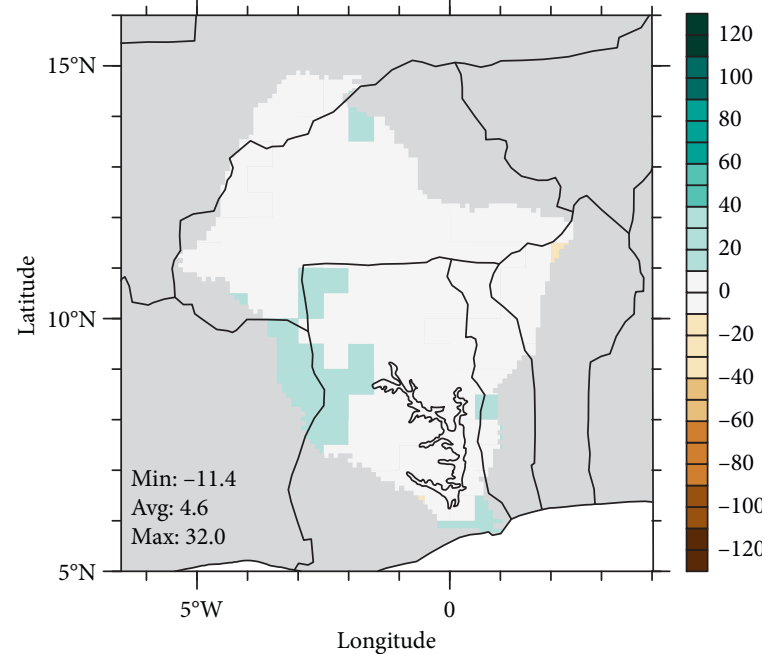

(a)

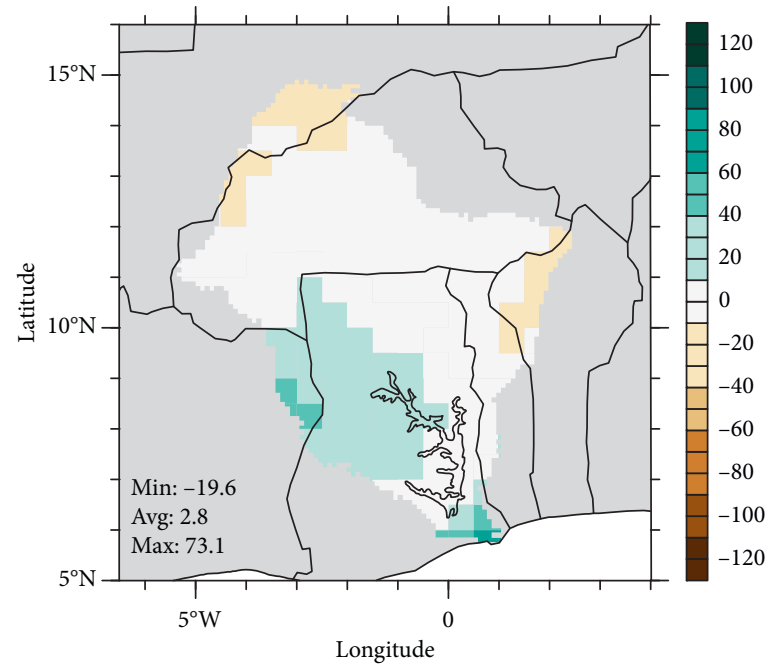

(c)

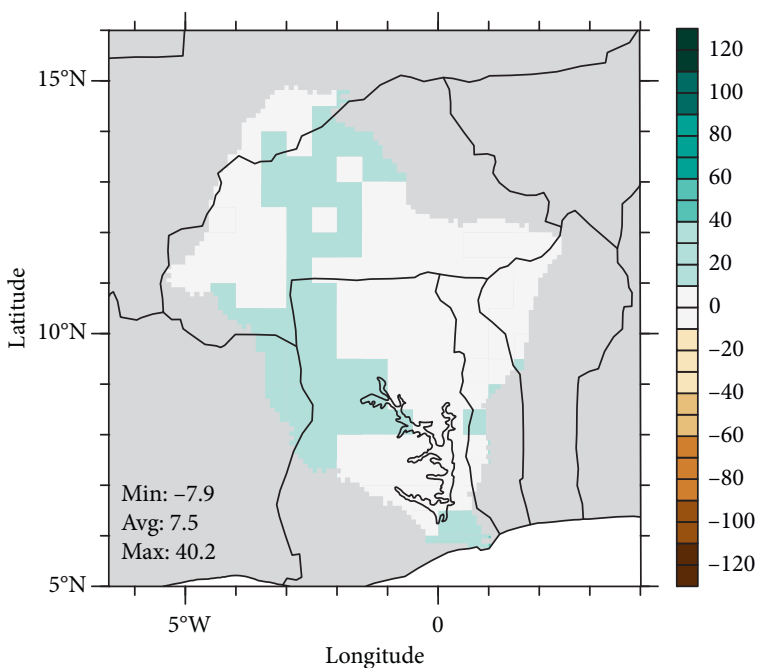

(b)

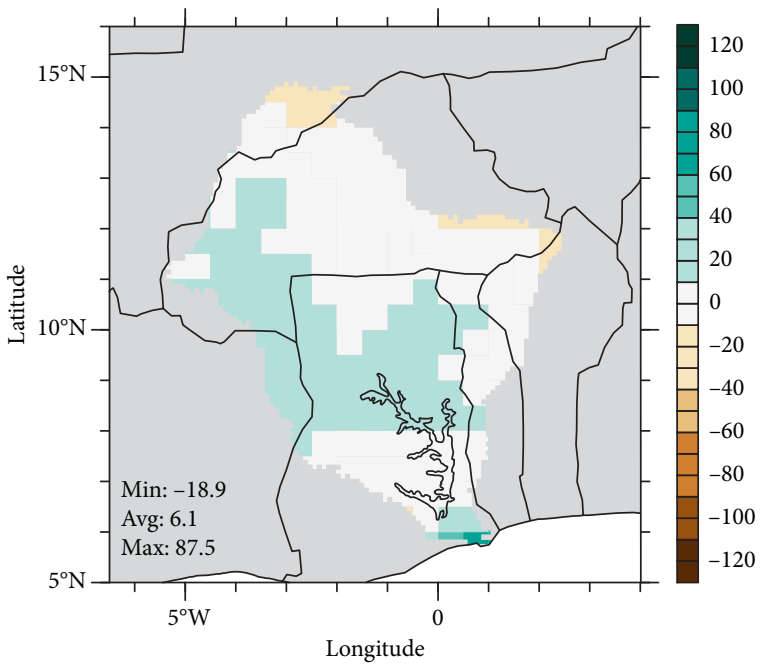

(d)

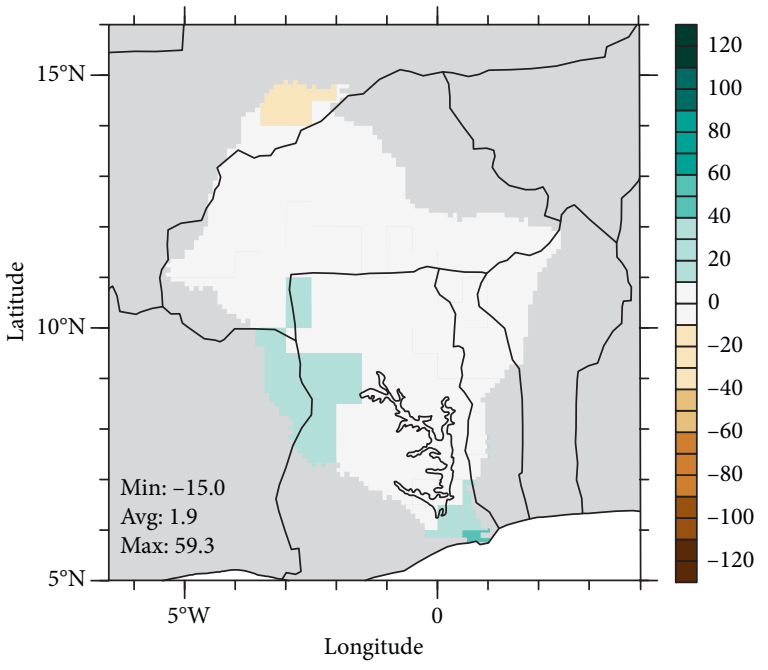

(e)

FIgURE 5: The climatological (1950-2004) mean bias in the annual total precipitation for the models: CESM1-BGC (a), CCSM4 (b), NorESM1-M (c), MPI-ESM-MR (d), and ensemble mean (e), simulating the observed climatological mean relatively well over the Volta Basin. 


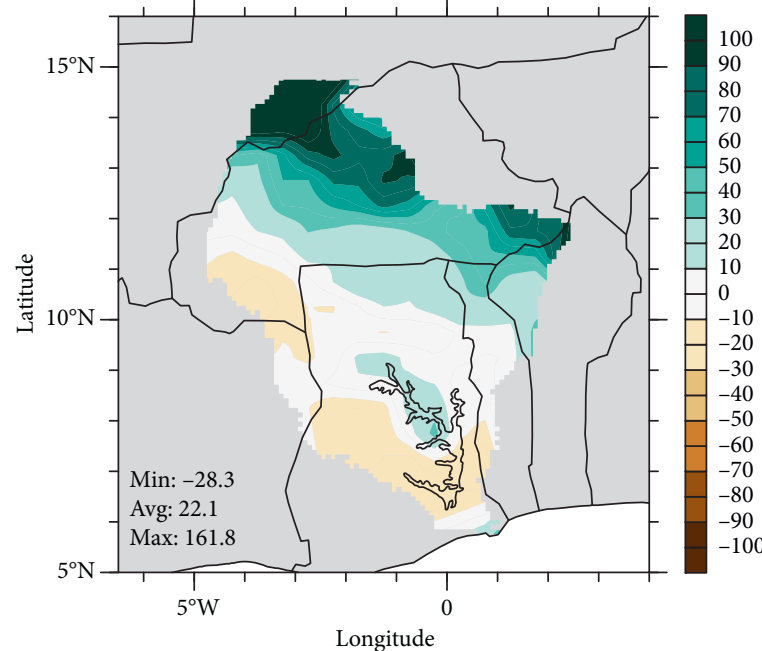

(a)

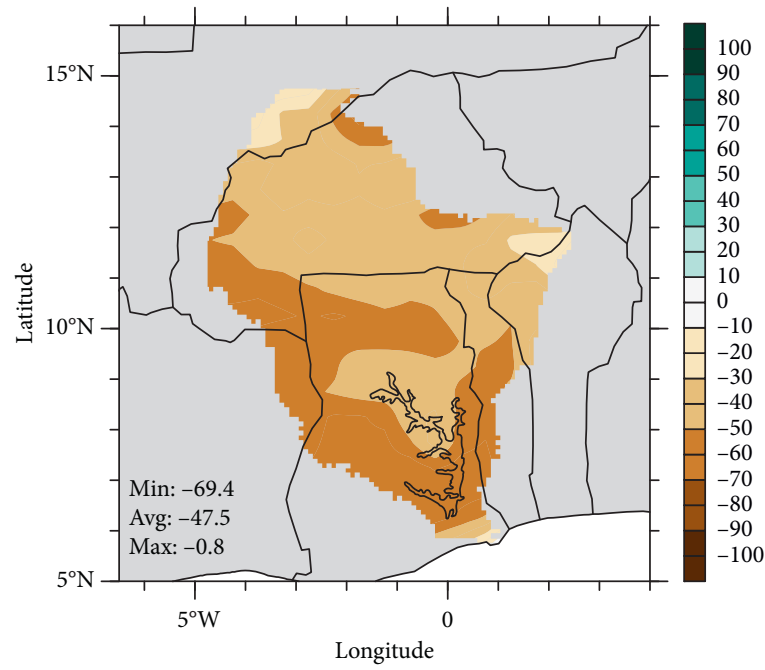

(c)

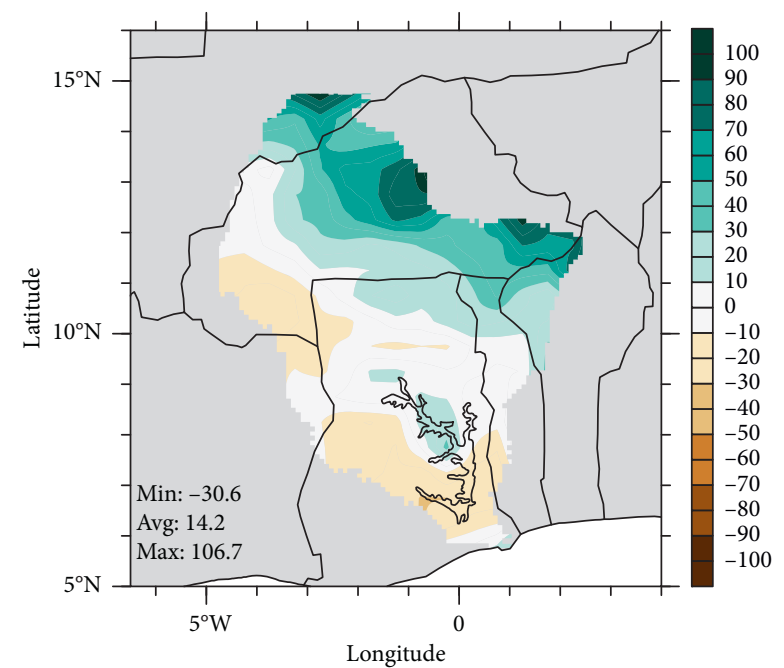

(b)

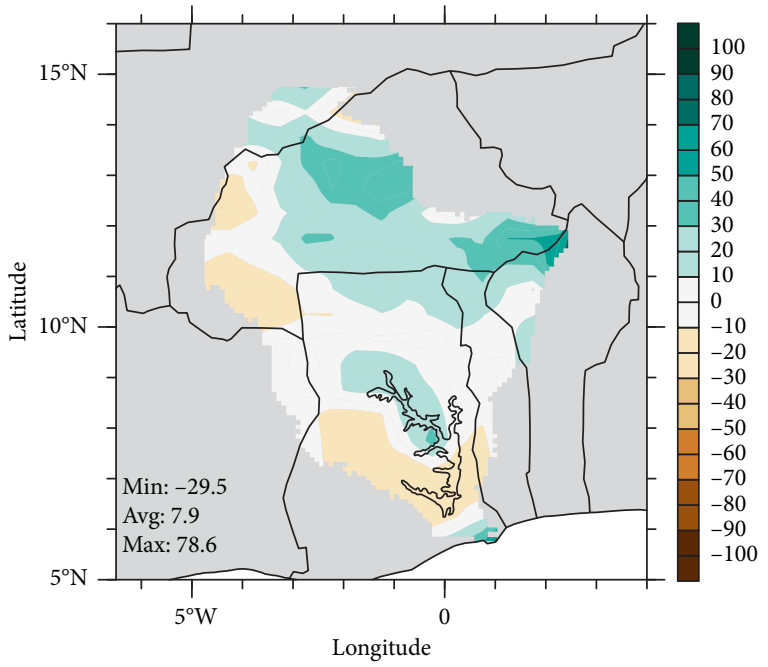

(d)

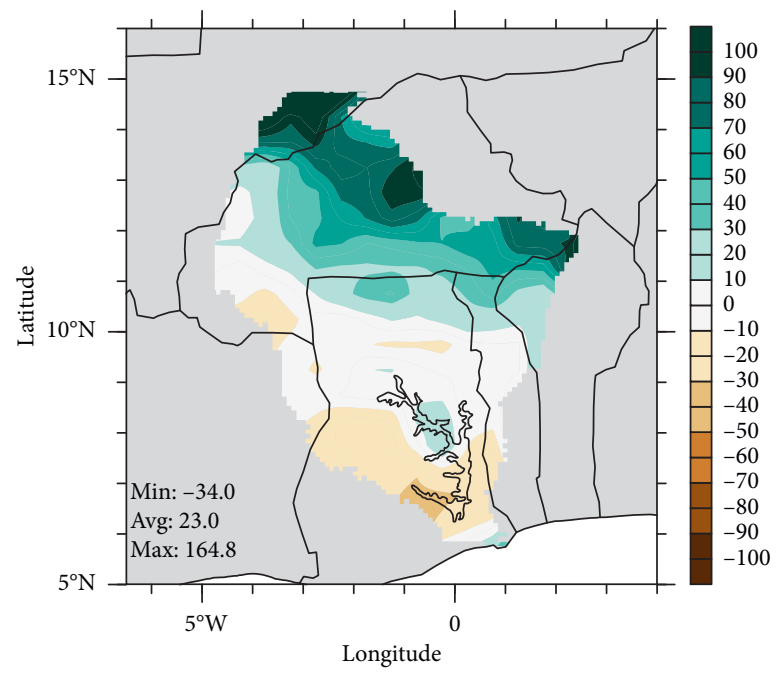

(e)

Figure 6: The climatological (1950-2004) mean bias in the seasonal totals of the models: CCSM4 (a), CESM1-BGC (b), MPI-ESM-MR (c), NorESM1-M (d), and ensemble mean (e), with least annual climatological mean biases for the dry season over the Volta Basin. 


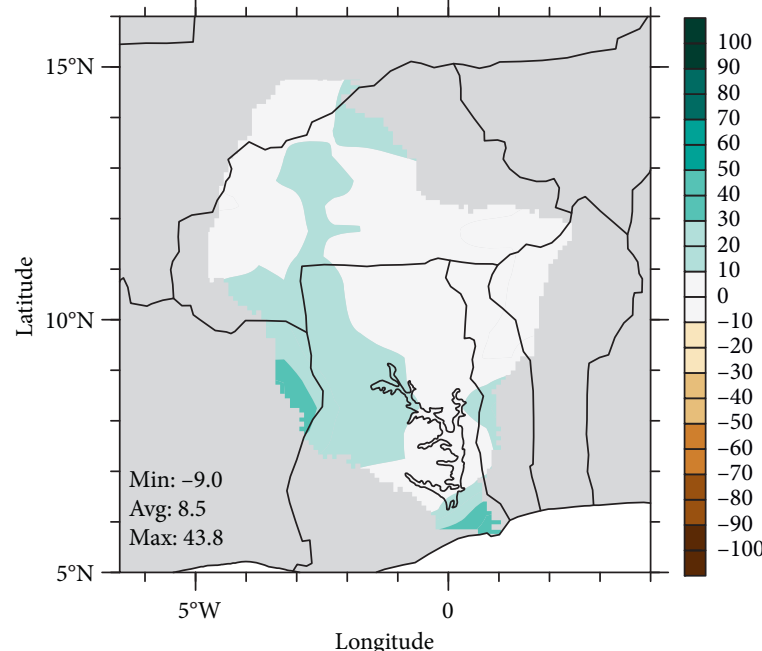

(a)

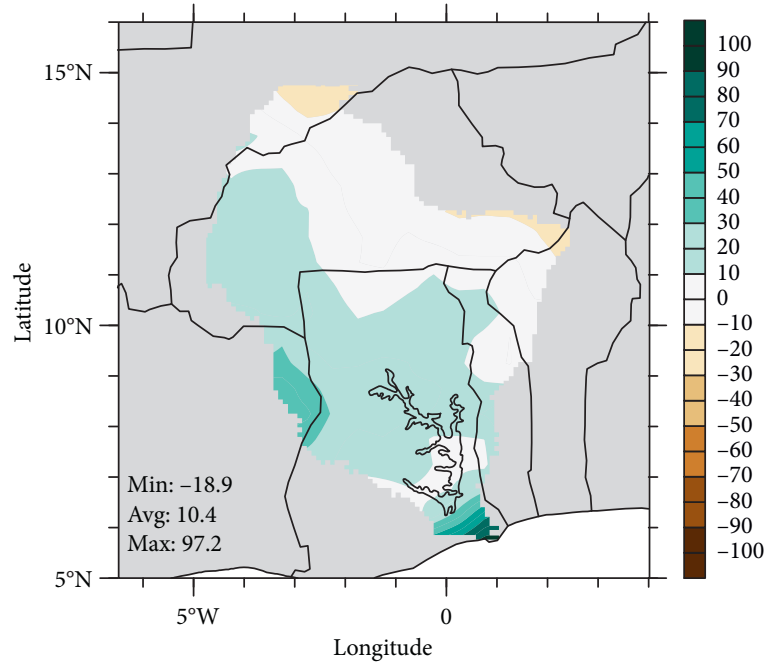

(c)

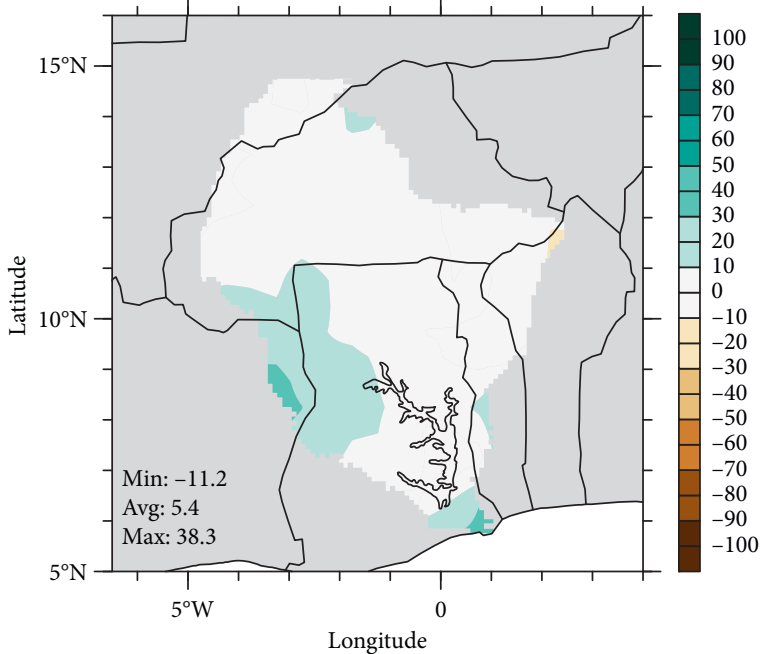

(b)

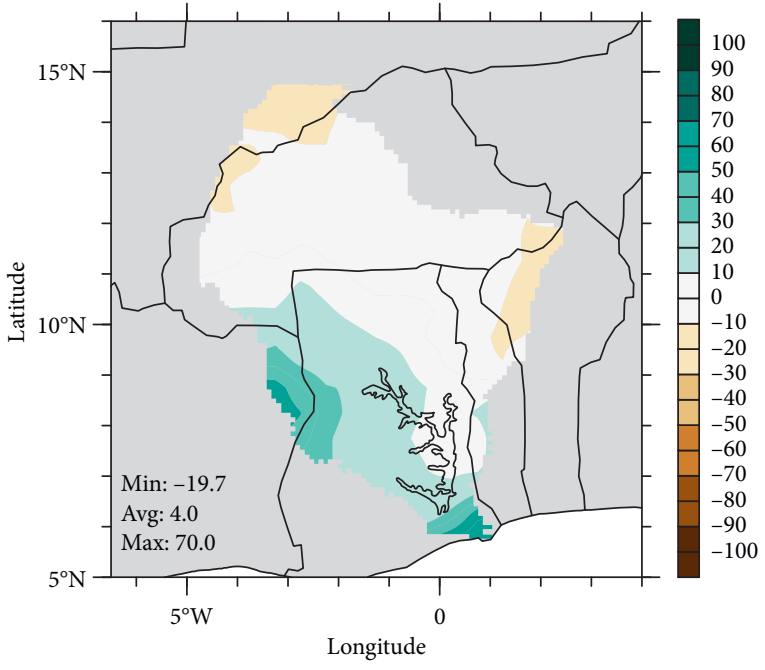

(d)

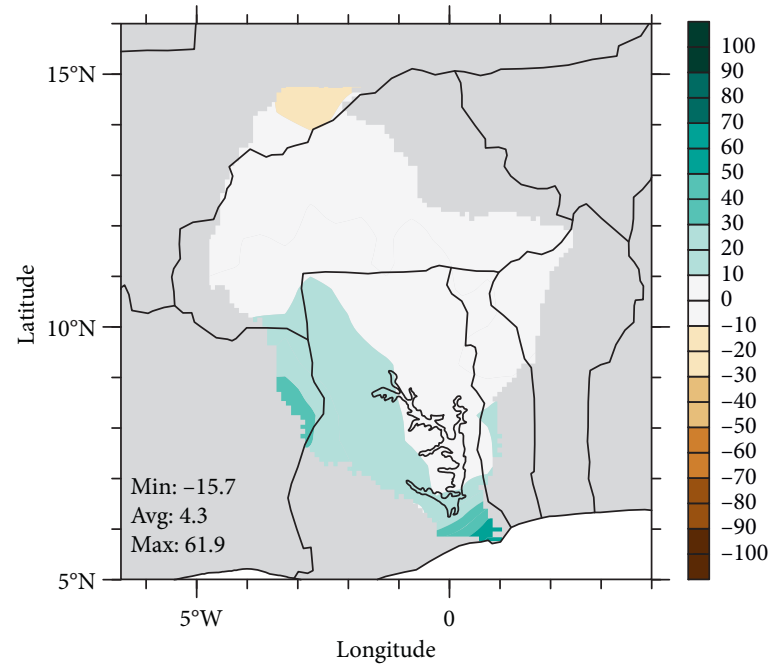

(e)

FIgURE 7: The climatological (1950-2004) mean bias in the seasonal totals of the models: CCSM4 (a), CESM1-BGC (b), MPI-ESM-MR (c), NorESM1-M (d), and ensemble mean (e), with least annual climatological mean biases for the rainy season over the Volta Basin. 


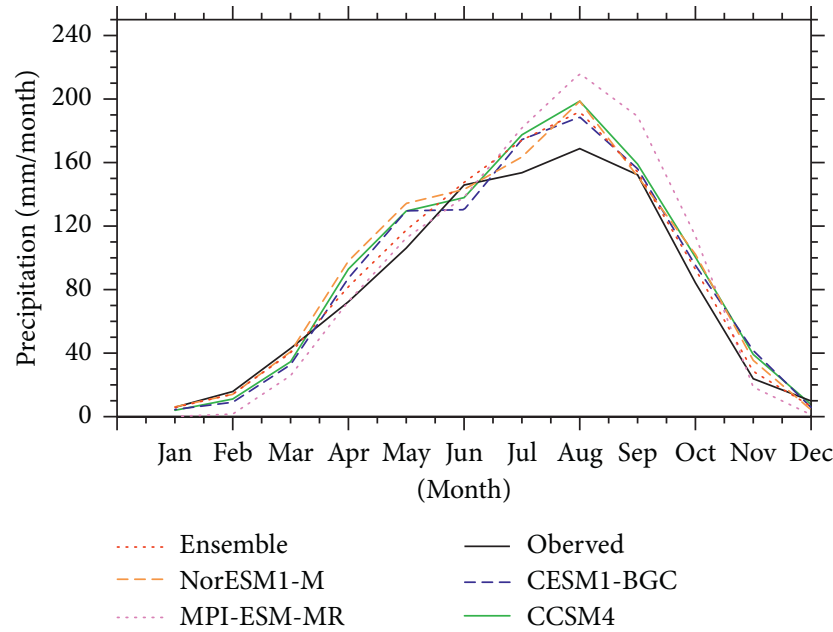

(a)

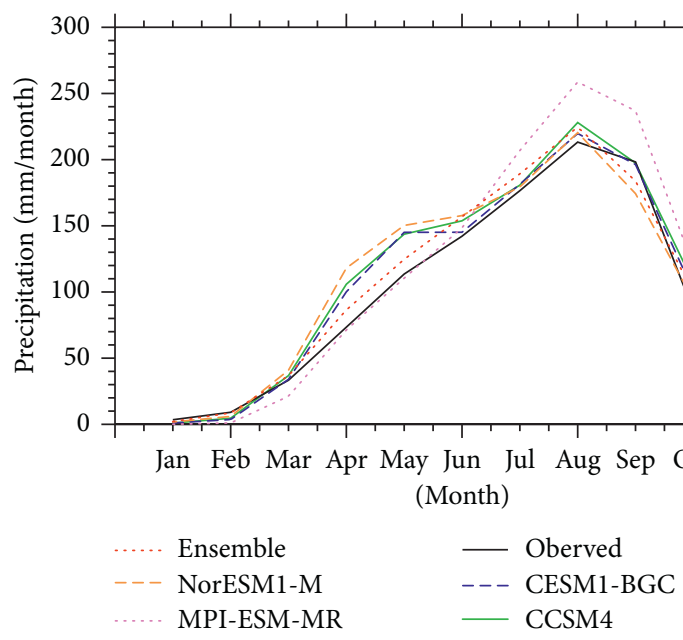

(c)

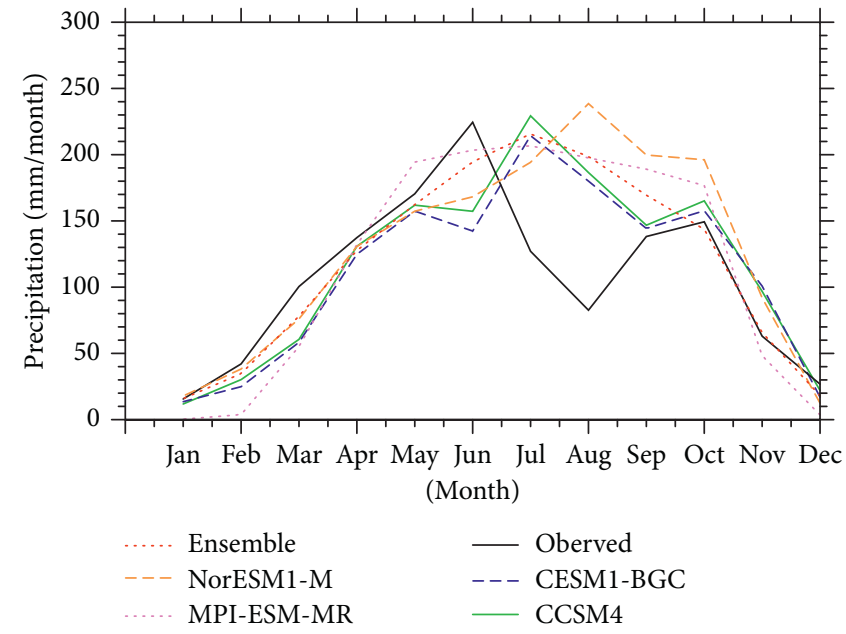

(b)

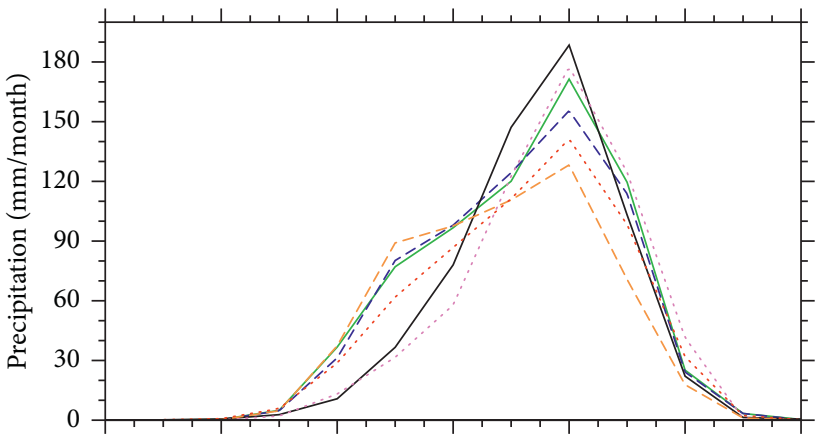

Jan Feb Mar Apr May Jun Jul Aug Sep Oct Nov Dec (Month)

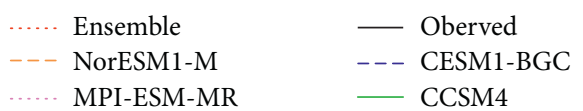

(d)

FIgURe 8: Annual cycles of monthly total precipitation for the period mean showing the bimodal (over the GC (b)) and the unimodal patterns (over the VB (a), the SD (c), and the SA (d)).

to simulate the unimodal (over the VB, the SD, and the SA) and the bimodal (over the GC) nature of the precipitation pattern [58] is examined. For the GC, precipitation increases from January and peaks in June. This is the first and major peak. Precipitation then decreases in July to a minimum in August and then increases until it peaks again in September which is the second and minor peak [58]. For the whole basin, the $\mathrm{SD}$, and the SA, maximum precipitation occurs in August [59]. The observed data used (Figure 8) also confirm these cycles for the various belts.

For the entire Volta Basin, the models are able to simulate the unimodal pattern of precipitation. The MPIESM-MR $(240.5 \mathrm{~mm})$ overestimates the observed maximum precipitation $(199.4 \mathrm{~mm})$, which occurs in August, while the CESM1-BGC $(202.8 \mathrm{~mm})$, the ensemble mean $(204.2 \mathrm{~mm})$, and the NorESM1-M $(200.8 \mathrm{~mm})$ are all able to simulate the maximum observed precipitation $(209.5 \mathrm{~mm})$ well.

For the Guinea Coast, the models are unable to simulate the bimodal nature accurately; for example, CESM1-BGC simulates early peaks, while others, for instance, CCSM4, simulate late peaks. Generally, most of the models overestimate the observed precipitation over the coast especially in the months of July and August. The ensemble mean of the models simulates a unimodal pattern of precipitation.

For the Soudano-Sahel, all the models are able to simulate the maximum precipitation which occurs in August. The MPI-ESM-MR although simulates the peak overestimates the observed precipitation. The NorESM1-M $(214.63 \mathrm{~mm})$, the CESM1-BGC $(216.74 \mathrm{~mm})$, the CCSM4 $(224.34 \mathrm{~mm})$, and the ensemble mean $(220.39 \mathrm{~mm})$ are all able to simulate the maximum precipitation close to the observed precipitation $(216.56 \mathrm{~mm})$.

For the Sahel, all the models underestimate the maximum precipitation $(209.5 \mathrm{~mm})$ with the exception of the MPI-ESM-MR $(211.5 \mathrm{~mm})$ which is able to simulate well the maximum observed precipitation.

The models' ability to simulate precipitation patterns (unimodal or bimodal) is dependent on their abilities to simulate the meridional movement of the intertropical convergent zone (ITCZ) [52, 60,61]. The models have less 
TABLE 2: Trend test for the Volta Basin rainy and dry seasons.

\begin{tabular}{|c|c|c|c|c|c|}
\hline & $Z$ & $p$ value & Slope & $p$ value (change point) & Change point year \\
\hline \multicolumn{6}{|c|}{ Dry season (NDJFMA) } \\
\hline Observed & -2.9 & 0.004 & -0.85 & 0.003 & 1970 \\
\hline CCSM4 & -1.5 & 0.135 & -0.53 & 0.419 & 1960 \\
\hline CESM1-BGC & 0.9 & 0.376 & 0.28 & 0.527 & 1981 \\
\hline MPI-ESM-MR & 1.8 & 0.079 & 0.51 & 0.338 & 1995 \\
\hline NorESM1-M & 1.3 & 0.182 & 0.30 & 0.527 & 1976 \\
\hline Ensemble & -0.8 & 0.429 & -0.05 & 0.415 & 1967 \\
\hline \multicolumn{6}{|c|}{ Rainy season (MJJASO) } \\
\hline Observed & -2.3 & 0.022 & -1.58 & 0.024 & 1970 \\
\hline CCSM4 & -0.1 & 0.919 & -0.09 & 1.384 & 1965 \\
\hline CESM1-BGC & 1.3 & 0.207 & 1.04 & 0.130 & 1983 \\
\hline MPI-ESM-MR & 1.8 & 0.079 & 0.51 & 0.338 & 1995 \\
\hline NorESM1-M & -0.6 & 0.532 & -0.56 & 0.603 & 1957 \\
\hline Ensemble & 1.8 & 0.076 & 0.39 & 0.059 & 1985 \\
\hline
\end{tabular}

Table 3: Trend test for the Guinea Coast major rainy/dry and minor rainy/dry seasons.

\begin{tabular}{|c|c|c|c|c|c|}
\hline & $Z$ & $p$ value & Slope & $p$ value (change point) & Change point year \\
\hline \multicolumn{6}{|c|}{ Major dry season (DJFM) } \\
\hline Observed & -4.6 & $5.14 E-06$ & -1.83 & 0.0002 & 1979 \\
\hline CCSM4 & -0.9 & 0.368 & -0.27 & 0.513 & 1955 \\
\hline CESM1-BGC & -0.2 & 0.828 & -0.04 & 0.885 & 1979 \\
\hline MPI-ESM-MR & -1.8 & 0.079 & -0.52 & 0.383 & 1970 \\
\hline NorESM1-M & -1.0 & 0.303 & -0.21 & 0.317 & 1963 \\
\hline Ensemble & -2.9 & 0.003 & -0.16 & 0.009 & 1972 \\
\hline \multicolumn{6}{|c|}{ Major rainy season $(A M J)$} \\
\hline Observed & -1.2 & 0.212 & -0.69 & 0.027 & 1970 \\
\hline CCSM4 & 0.1 & 0.942 & 0.04 & 1.283 & 1961 \\
\hline CESM1-BGC & 0.0 & 0.977 & 0.01 & 1.558 & 1961 \\
\hline MPI-ESM-MR & 2.0 & 0.050 & 1.31 & 0.269 & 1970 \\
\hline NorESM1-M & -0.8 & 0.400 & -0.46 & 1.019 & 1967 \\
\hline Ensemble & 0.1 & 0.905 & 0.02 & 1.209 & 1984 \\
\hline \multicolumn{6}{|c|}{ Minor dry season (JA) } \\
\hline Observed & 1.7 & 0.089 & 1.44 & 0.157 & 1962 \\
\hline CCSM4 & -1.1 & 0.276 & -0.88 & 0.603 & 1957 \\
\hline CESM1-BGC & 0.1 & 0.885 & 0.12 & 0.701 & 1965 \\
\hline MPI-ESM-MR & 0.8 & 0.408 & 0.50 & 0.635 & 1987 \\
\hline NorESM1-M & 0.2 & 0.850 & 0.15 & 0.940 & 1984 \\
\hline Ensemble & -1.9 & 0.054 & -0.3 & 0.020 & 1968 \\
\hline \multicolumn{6}{|c|}{ Minor rainy season (SON) } \\
\hline Observed & -1.9 & 0.063 & -1.14 & 0.061 & 1964 \\
\hline CCSM4 & -0.7 & 0.486 & -0.52 & 0.882 & 1975 \\
\hline CESM1-BGC & 1.2 & 0.245 & 0.72 & 0.146 & 1983 \\
\hline MPI-ESM-MR & 3.8 & 0.0001 & 2.43 & 0.002 & 1974 \\
\hline NorESM1-M & 0.2 & 0.805 & 0.146 & 1.160 & 1977 \\
\hline Ensemble & 0.4 & 0.687 & 0.06 & 0.620 & 1991 \\
\hline
\end{tabular}

difficulty in simulating the unimodal pattern over the basin, the Soudano-Sahel, and the Sahel. Over the Guinea Coast, the bimodal pattern is poorly simulated. The models had less difficulty in simulating the dry season precipitation due to the less spatial variation in precipitation during the dry season. Compared to the dry season, precipitation varies spatially during rainy seasons due to differential occurrence of convection activities across the regions, and another factor is the coarse resolution of the GCMs which makes it difficult to simulate these mesoscale features (e.g., $[57,62,63]$ ).
3.3.2. Seasonal Trend Analysis. The Mann-Kendall test was used to analyze the trend in the rainy and dry seasons over the GC, SD, SA, and VB. The results are presented in Tables $2-5$. The trend results in this study have been evaluated at the 5\% significant level (95\% confidence level), and the corresponding threshold $(Z)$ value is \pm 1.96 . This implies that the null hypothesis is rejected when $\left|Z_{S}\right| \geq Z_{\alpha / 2}$ in (8)-(10) at the $\alpha=0.05$ level of significance.

For the change-point detection (12)-(14), Pettitt's test was used to indicate the year $\left(K_{T}\right)$ of change in the trend and 
TABle 4: Trend test for the Soudano-Sahel rainy and dry seasons.

\begin{tabular}{lccccc}
\hline & $Z$ & $p$ value & Slope & $p$ value (change point) & Change point year \\
\hline Dry season (NDJFMA) & & & & & 0.013 \\
Observed & -2.3 & 0.024 & -0.75 & 0.513 & 1970 \\
CCSM4 & -1.4 & 0.155 & -0.55 & 0.651 & 1994 \\
CESM1-BGC & 0.7 & 0.459 & 0.26 & 0.235 & 1981 \\
MPI-ESM-MR & 1.9 & 0.052 & 0.65 & 0.771 & 1995 \\
NorESM1-M & 1.1 & 0.276 & 0.27 & 0.556 & 1986 \\
Ensemble & -0.9 & 0.387 & -0.05 & & 1967 \\
Rainy season (MJJASO) & & & 0.157 & 1.039 & 1972 \\
Observed & -1.7 & 0.081 & -1.29 & 0.176 & 1965 \\
CCSM4 & -0.1 & 0.896 & -0.15 & 0.009 & 1986 \\
CESM1-BGC & 1.4 & 0.168 & 1.50 & 0.587 & 1957 \\
MPI-ESM-MR & 3.6 & 0.0003 & 3.89 & 0.035 & 1985 \\
NorESM1-M & -0.6 & 0.561 & -0.44 & 0.41 & \\
Ensemble & 2.0 & 0.047 & & & \\
\hline
\end{tabular}

Table 5: Trend test for the Sahel rainy and dry seasons.

\begin{tabular}{lccccc}
\hline & $Z$ & $p$ value & Slope & $p$ value (change point) & Change point year \\
\hline Dry season (NDJFMA) & & & & & 0.979 \\
Observed & -0.2 & 0.873 & -0.01 & 0.042 & 1969 \\
CCSM4 & -1.8 & 0.074 & -0.40 & 0.110 & 1994 \\
CESM1-BGC & 1.1 & 0.264 & 0.17 & 0.106 & 1981 \\
MPI-ESM-MR & 2.8 & 0.005 & 0.27 & 0.513 & 1965 \\
NorESM1-M & 1.1 & 0.251 & 0.28 & 0.76 & 1974 \\
Ensemble & -0.9 & 0.355 & -0.04 & & 1967 \\
Rainy season (MJJASO) & & & & 1.201 & 1970 \\
Observed & -4.8 & $1.54 E-06$ & -3.84 & 0.115 & 1994 \\
CCSM4 & 0.3 & 0.760 & 0.28 & 0.106 & 1983 \\
CESM1-BGC & 1.2 & 0.245 & 0.82 & 0.771 & 1965 \\
MPI-ESM-MR & 3.3 & 0.001 & 3.40 & 0.071 & 1985 \\
NorESM1-M & -0.6 & 0.561 & -0.28 & 0.60 & \\
Ensemble & 2.2 & 0.025 & & & \\
\hline
\end{tabular}

the significance, which is also analyzed at the $95 \%$ confidence level.

Table 2 shows results for the trends in seasonal (dry and rainy seasons) precipitation over the Volta Basin. There is a significant $(99.6 \%$ confidence level) decrease in dry seasonal (November (Nov), December (Dec), January (Jan), February (Feb), March (Mar), and April (Apr)) precipitation over the basin for the study period (1950-2004) as seen in the observed data. The magnitude of the decrease is $0.85 \mathrm{~mm}$ per season. This denoted an increase in dryness over the basin during the dry seasons over that 55-year period. All the models are unable to simulate this decreasing trend with the exception of the CCSM4 and the EM which simulate a decreasing trend of 0.54 and $0.05 \mathrm{~mm}$ per season, respectively. For the rainy season (May, June (Jun), July (Jul), August (Aug), September (Sept), and October (Oct)), there is also a significant (97.8\% confidence level) decreasing trend in seasonal precipitation with the magnitude of $1.58 \mathrm{~mm}$ per season. The CCSM4 and the NorESM1-M simulate the decreasing trend, with the NorESM1-M ( $0.6 \mathrm{~mm}$ per season) simulating the observed trend relatively well. Over the Volta Basin generally, there is a decrease in seasonal precipitation as shown in the results.
For the change-point detection (the last two columns of Table 2), there is a change in the trend which occurs in 1970 for both seasons, that is, statistically significant (about $99 \%$ and $98 \%$ confidence levels for dry and rainy seasons, resp.).

All the models are unable to reproduce this change point.

Table 3 gives the results of the major dry/rainy and the minor dry/rainy seasons over the Guinea Coast. In the major dry season (Dec, Jan, Feb, and Mar), there is a significant (99.9\% confidence level) decrease in seasonal precipitation of $1.83 \mathrm{~mm}$ per season. All the models including the EM are able to simulate this decreasing trend, with the MPI-ESM-MR ( $0.52 \mathrm{~mm}$ per season) doing relatively well as compared to the other models. A statistically significant (about 99\% confidence level) change in the trend occurs in 1979, in which all the models are unable to simulate with the exception of the CESM1-BGC. In the major rainy season (Apr, May, and Jun), there is a decreasing trend in seasonal precipitation which is not statistically significant. With the exception of the NorESM1-M (decreasing at $0.46 \mathrm{~mm}$ per season) which is able to simulate the decreasing trend, all the models simulate an increasing trend. The change-point year as seen in the observational data occurs in 1970, and it is statistically significant (about 97\% confidence level). Only 
the MPI-ESM-MR is able to reproduce this change point. For the minor dry season (Jul and Aug), an increasing trend, although statistically not significant, is observed. All the models simulate this increasing trend with the exception of the CCSM4 and the EM. The MPI-ESM-MR best simulates the observed trend. The change-point year occurs in 1962. Although this change point is statistically not significant, it is not simulated by the models. In the minor rainy season (Sept, Oct, and Nov), the CCSM4 simulates the decreasing trend in the observed seasonal precipitation which is statistically insignificant. All the other models simulate an increasing trend. Also, all the models are unable to simulate the change-point year of 1964 which is statistically not significant.

In the Soudano-Sahel, the trend for the dry (Nov, Dec, Jan, Feb, Mar, and Apr) and rainy (May, Jun, Jul, Aug, Sept, and Oct) seasons is shown in Table 4. In the dry season, a decreasing trend which is statistically significant $(97.4 \%$ confidence level) is observed, with a magnitude of $0.75 \mathrm{~mm}$ per season. All the models simulate an increasing trend with the exception of the CCSM4 (decreasing trend at $0.55 \mathrm{~mm}$ per season) and the EM (decreasing trend at $0.1 \mathrm{~mm}$ per season). For the dry season, a decreasing trend of $1.3 \mathrm{~mm}$ per season, although statistically insignificant, is observed in the reference data. The NorESM1-M (decreasing trend at $0.44 \mathrm{~mm}$ per season) is able to simulate the decreasing trend well as compared to the other models.

The change-point year of the dry season occurs in 1970 which is statistically significant (about 99\% confidence level), while that of the rainy season occurs in 1972 which is not significant statistically. All the models are unable to simulate these change points in both seasons.

Table 5 shows the dry (Nov, Dec, Jan, Feb, Mar, and Apr) and rainy (May, Jun, Jul, Aug, Sept, and Oct) seasonal trends over the Sahel. In the dry season, a slight decreasing trend of $0.1 \mathrm{~mm}$ per season which is not significant statistically is observed. The CCSM4 $(0.4 \mathrm{~mm})$ and the EM $(0.04 \mathrm{~mm})$ simulate well this trend, whereas the rest of the models simulate an increasing trend. For the rainy season, there is a strong decrease in seasonal precipitation $(3.84 \mathrm{~mm}$ per season) which is significant ( $99.9 \%$ confidence level) in the observational data set. All the models simulate increasing trends with the exception of the NorESM1-M (decreasing trend at $0.28 \mathrm{~mm}$ per season) that simulates the decreasing trend, but the magnitude is far less than the observed trend.

The change-point year of the dry season although statistically insignificant occurs in 1969, while that of the rainy season occurs in 1970, but this is statistically significant. All the models are unable to simulate these change point years well.

Generally, there is a decrease in seasonal precipitation of the three belts and the basin. Dry seasons are becoming drier, while rainy season precipitation is decreasing. This trend, if it continues, could significantly affect the production of crops and also the shifting of the rainy season (e.g., [64-66]). The trends also show changes in the 1960s and 1970s, shown in the change-point years. This could be a result of the several droughts that occurred within the West African subregions in the 1960s-80s [67].
3.3.3. Temporal Seasonal Patterns. For the seasonal scale, the ability of the CCSM4, CESM1-BGC, NorESM1-M, MPIESM-MR, and ensemble mean of all the 18 models to simulate the temporal seasonal variability and the temporal precipitation patterns is presented. The first four models are selected because of their ability to simulate the observed precipitation on the annual time scale. The variability, the pattern, and the errors are represented by the normalized standard deviation, the correlation coefficient, and the rootmean-square difference, respectively, in the Taylor diagrams [68]. The results are presented for the standard seasons: winter (DJF), spring (MAM), summer (JJA), and fall (SON). In these diagrams (Figures 9-12), the correlation coefficient ( $r$ ) (main arc) and the root-mean-square (RMS) difference (inner arcs) between the models and the GPCC data, along with the standard deviation (SD) (horizontal axis/vertical axis), are all indicated by points. Also, models with negative correlation are represented below the diagrams. In addition to the three statistics, the biases between the models and the observed data are also included in the diagram, with right triangles giving positive biases and left triangles giving negative biases.

(1) Over the Entire Volta Basin. For the Volta Basin (Figure 9), the performances of the models vary for the four seasons. Temporal correlation for all the seasons and for all the models is less than 0.3. This indicates the models' inability to simulate the observed pattern in seasonal precipitation over the Volta Basin. In winter (DJF), all the models underestimate the observed variability $(\sigma<1)$ with the CCSM4 $(\sigma=0.6)$ and the ensemble mean (EM) $(\sigma=0.5)$ simulating variability close to the observed. In spring (MAM), the MPI-ESM-MR $(\sigma=2.3)$, the NorESM1-M $(\sigma=1.8)$, the CESM1-BGC $(\sigma=1.6)$, and the EM $(\sigma=1.6)$ simulate relatively high variability, whereas the CCSM4 $(\sigma=1.2)$ simulates variability close to the observed variability. In summer (JJA), high variability is simulated by the EM $(\sigma=1.5)$, the CESM1-BGC $(\sigma=1.4)$, the MPI-ESMMR $(\sigma=1.4)$, and the NorESM1-M $(\sigma=1.3)$, whereas the CCSM4 $(\sigma=1.2)$ is able to simulate variability close to the observed. In fall (SON), maximum variability is simulated by the MPI-ESM-MR $(\sigma=1.8)$ and NorESM1-M $(\sigma=1.5)$. However, the EM $(\sigma=1.1)$, the CCSM4 $(\sigma=1.1)$, and the CESM1-BGC $(\sigma=1.2)$ simulate variability close to the observed data. The CCSM4 and the EM relatively perform fairly well in simulating the observed variability over the entire basin.

(2) The Guinea Coast. Temporal correlations for all the models in all the seasons over the Guinea Coast (Figure 10) are also less than 0.3 . In winter again, all the models underestimate the observed variability with the CCSM4 $(\sigma=0.7)$ and the $\operatorname{EM}(\sigma=0.5)$ simulating variability close to the observed. In spring, the MPI-ESM-MR $(\sigma=1.9)$ and the EM $(\sigma=1.4)$ simulate fairly high variability. The NorESM1$\mathrm{M}(\sigma=0.9)$ and the CESM1-BGC $(\sigma=1.0)$ simulate variability close to the observed but fail totally in reproducing the observed pattern due to their negative correlations. The CCSM4 $(\sigma=0.6)$ reasonably simulates the observed variability. In summer, all the models underestimate the 


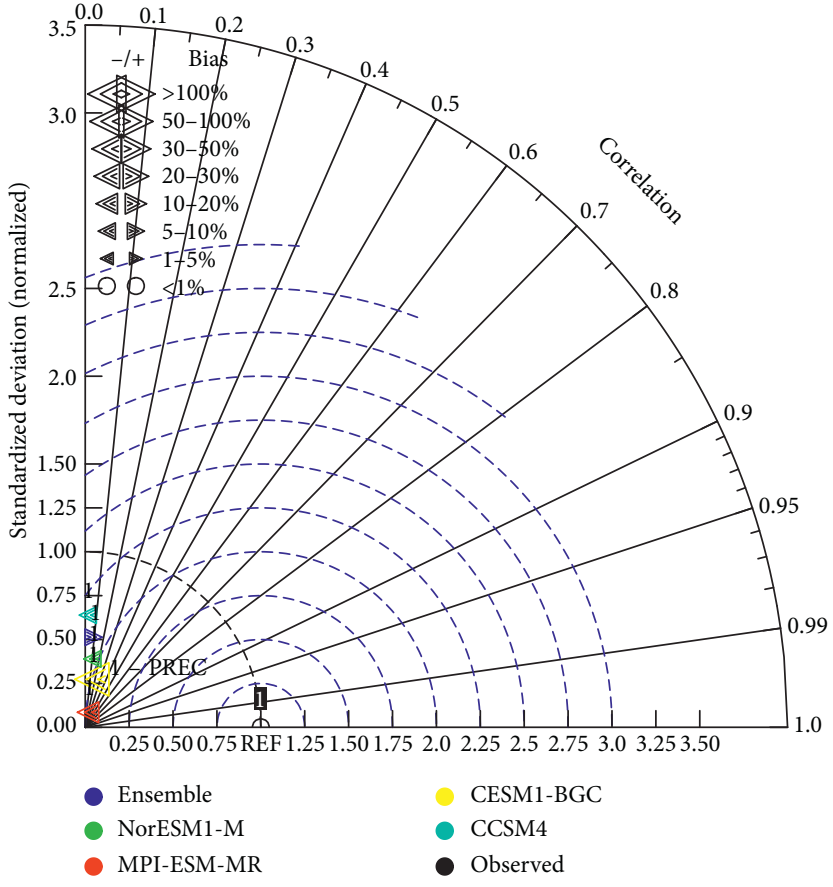

(a)

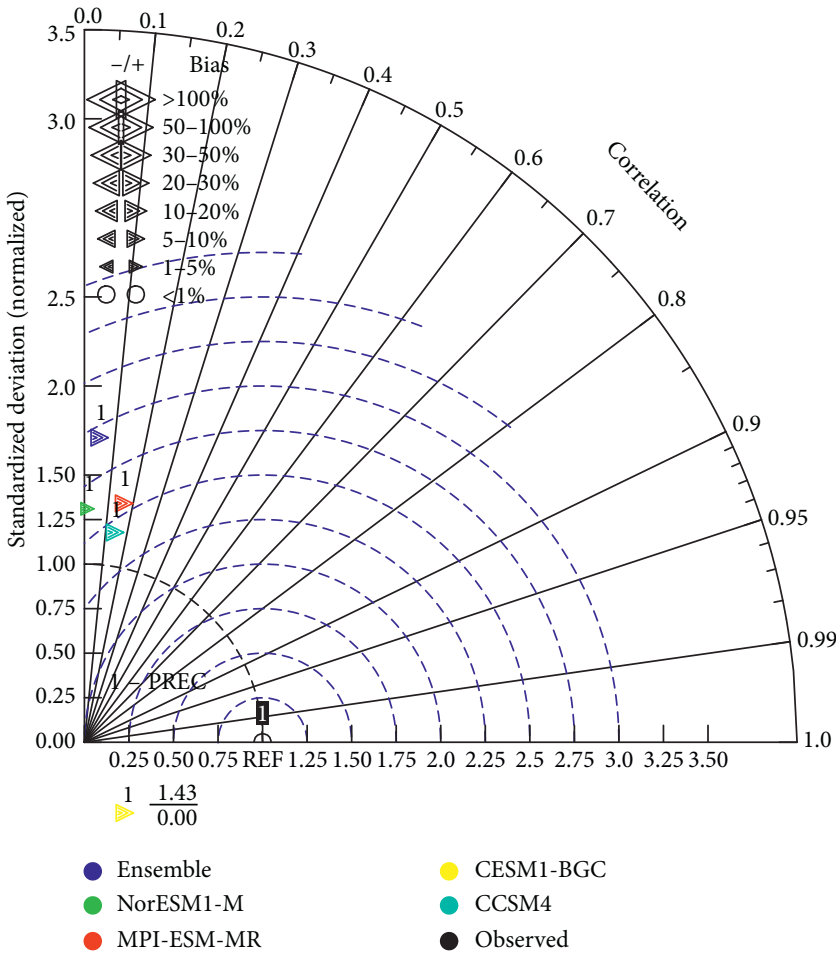

(c)

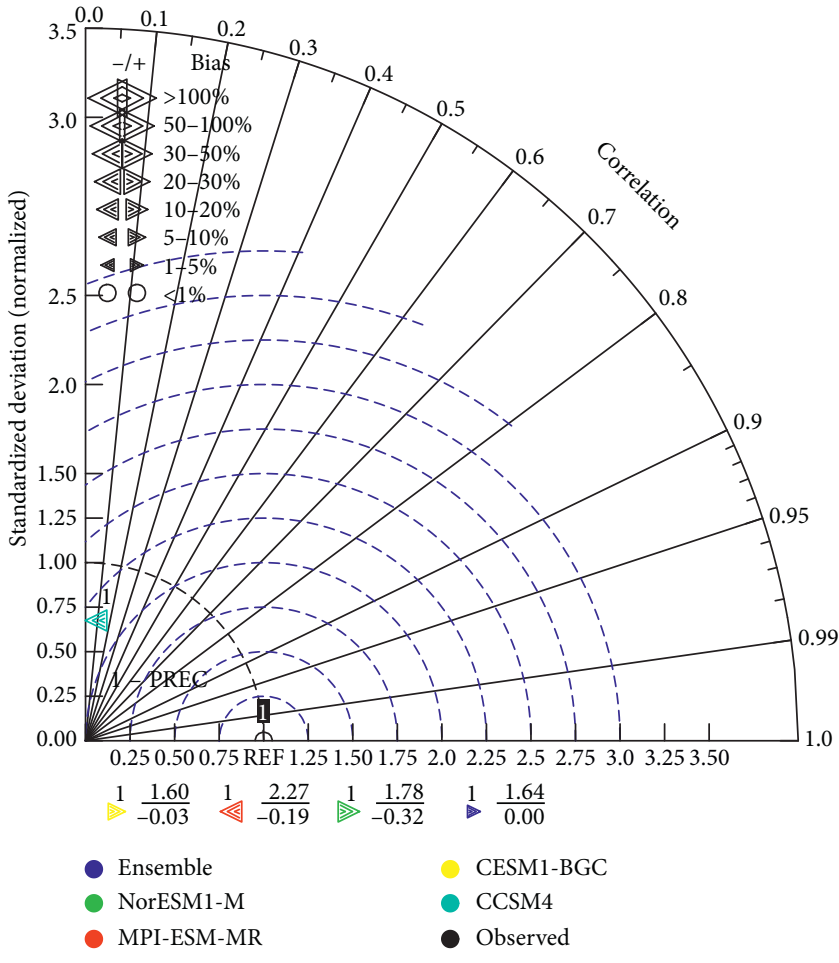

(b)

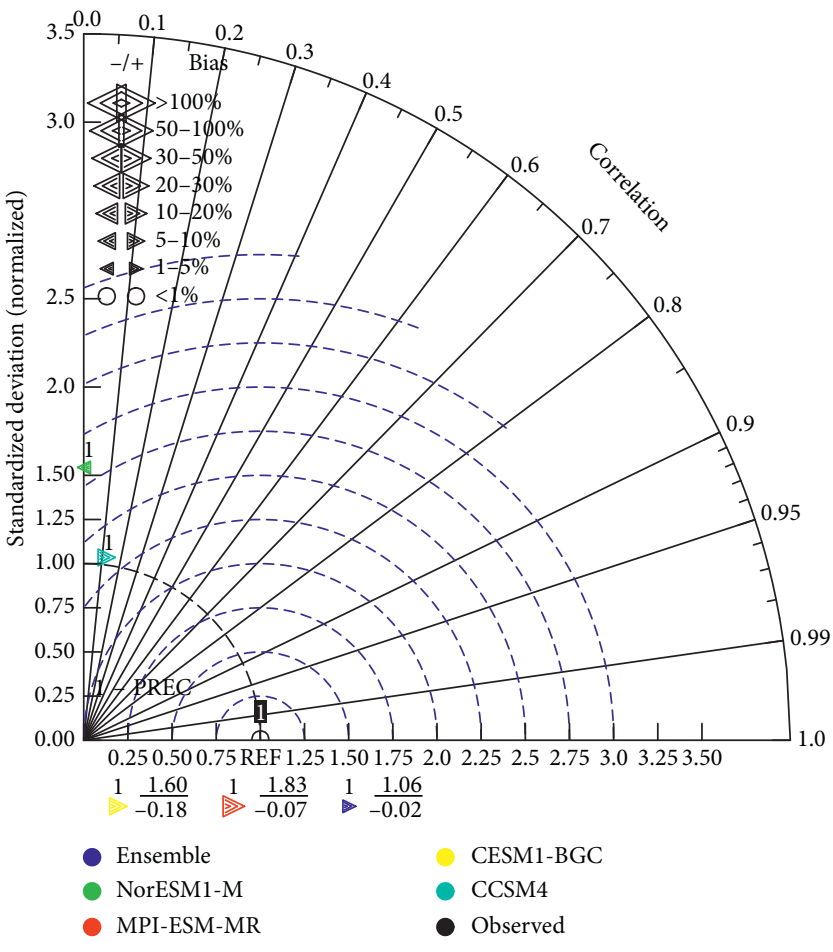

(d)

Figure 9: Taylor diagram for the Volta Basin showing the normalized standard deviation, the correlation, and the RMSE representing the variability, pattern, and errors, respectively, within the models and the reference data: DJF (a); MAM (b); JJA (c); SON (d). 


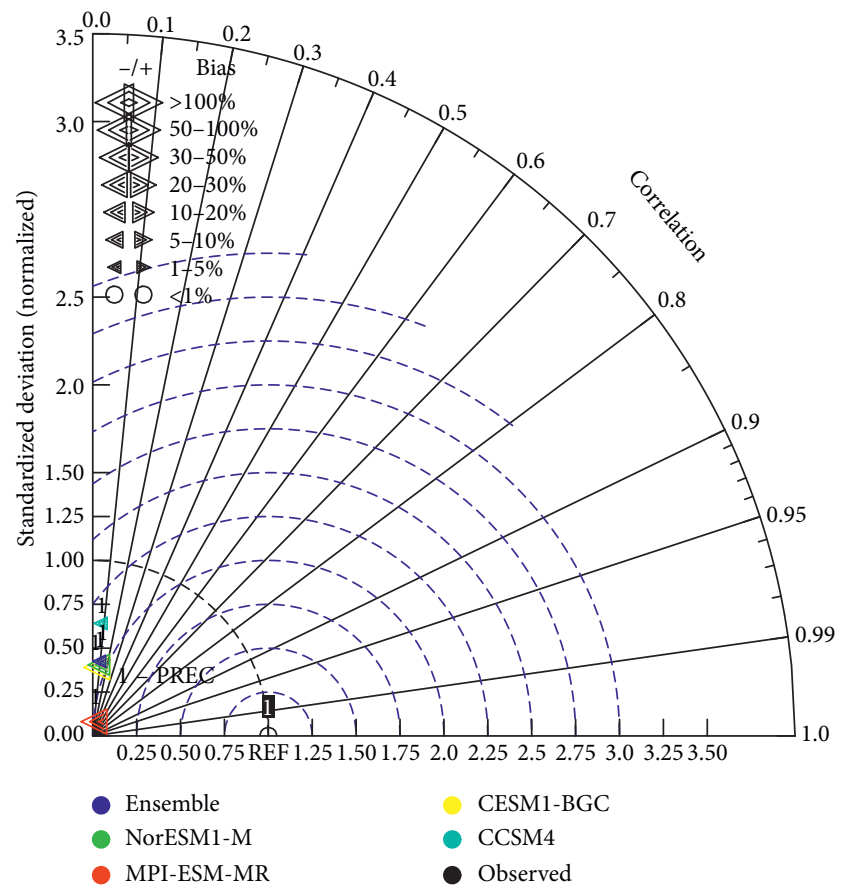

(a)

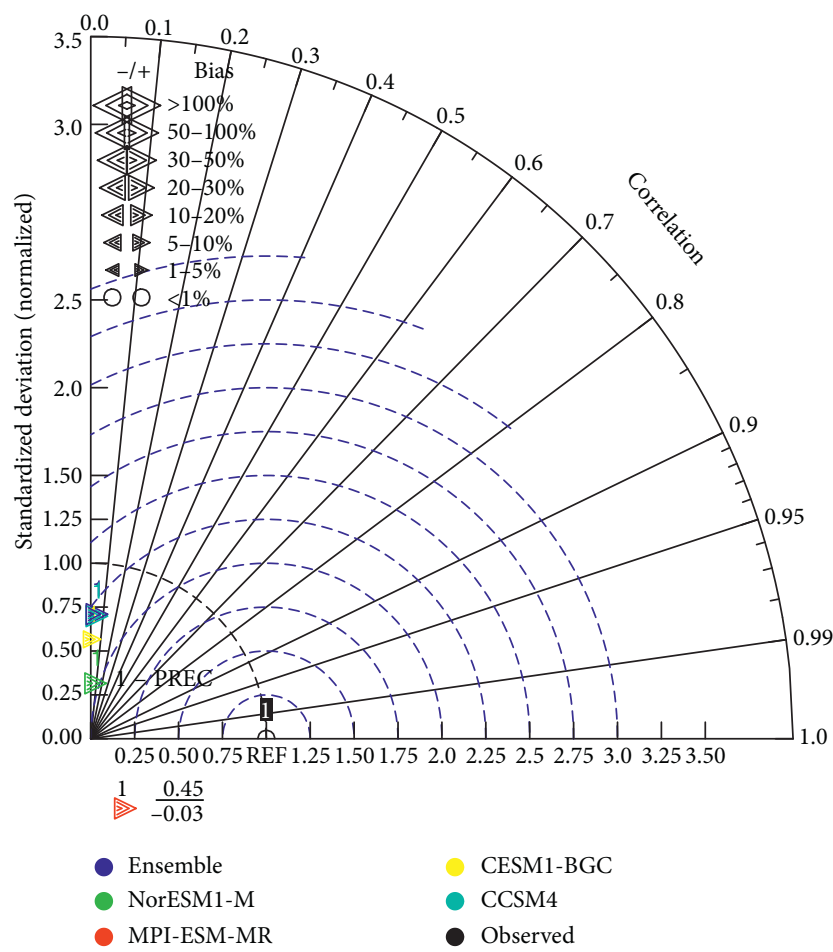

(c)

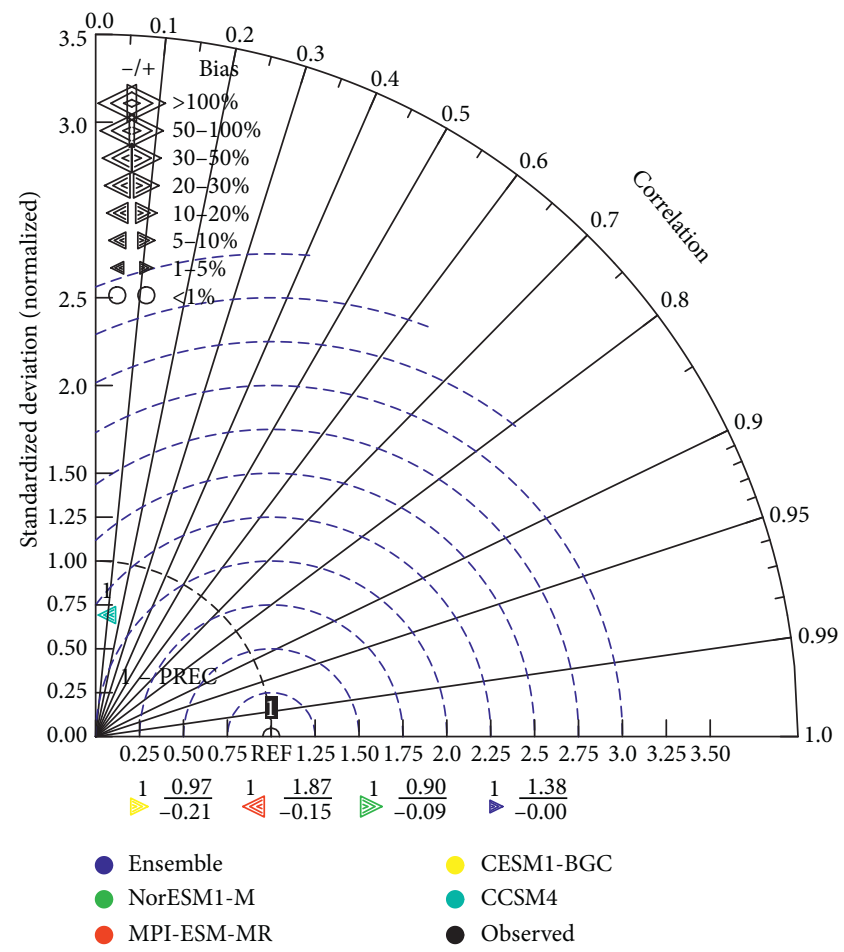

(b)

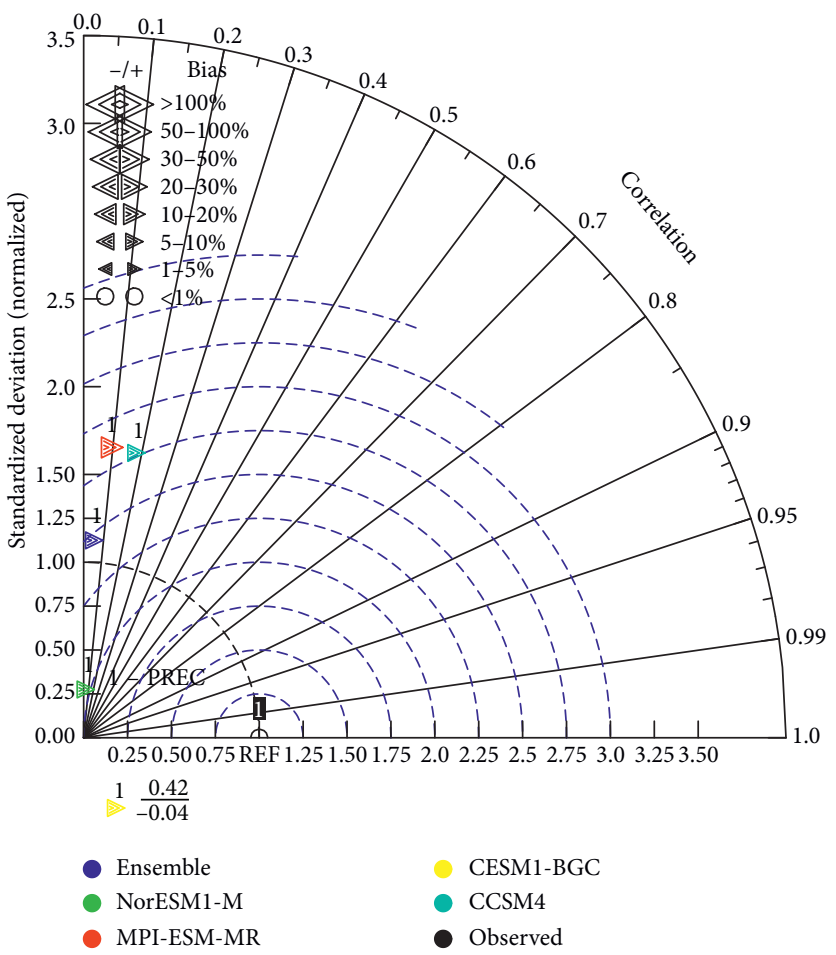

(d)

FIGURE 10: Taylor diagram for the Guinea Coast showing the normalized standard deviation, the correlation, and the RMSE representing the variability, pattern, and errors, respectively, within the models and the reference data: DJF (a); MAM (b); JJA (c); SON (d). 


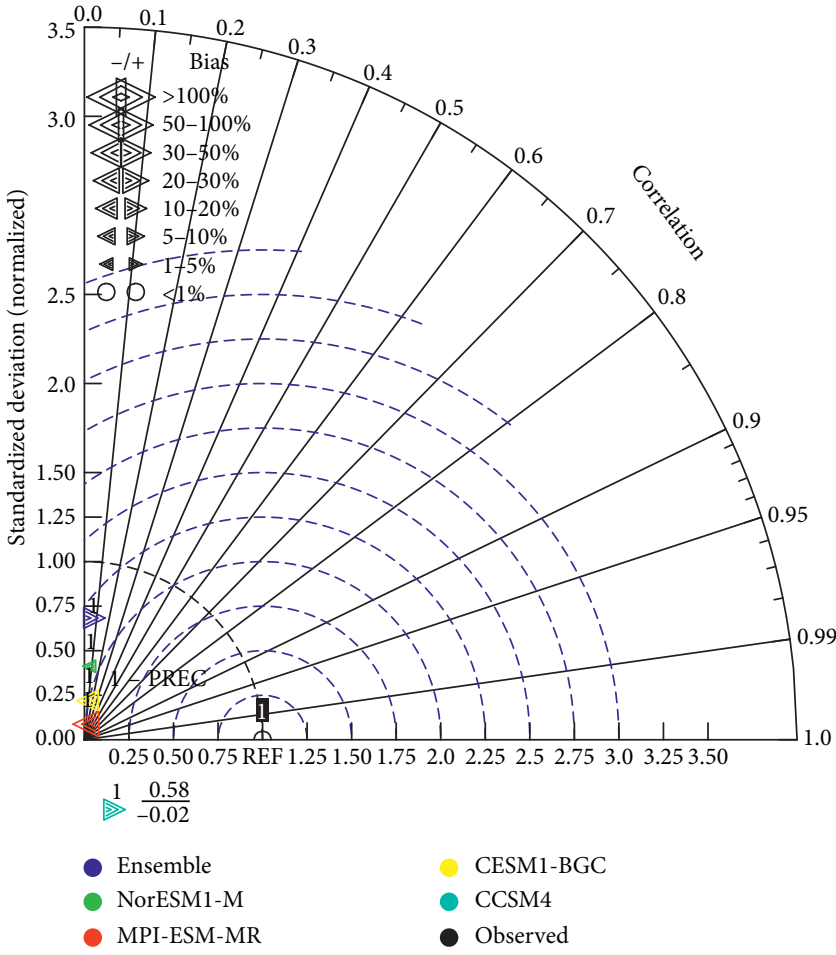

(a)

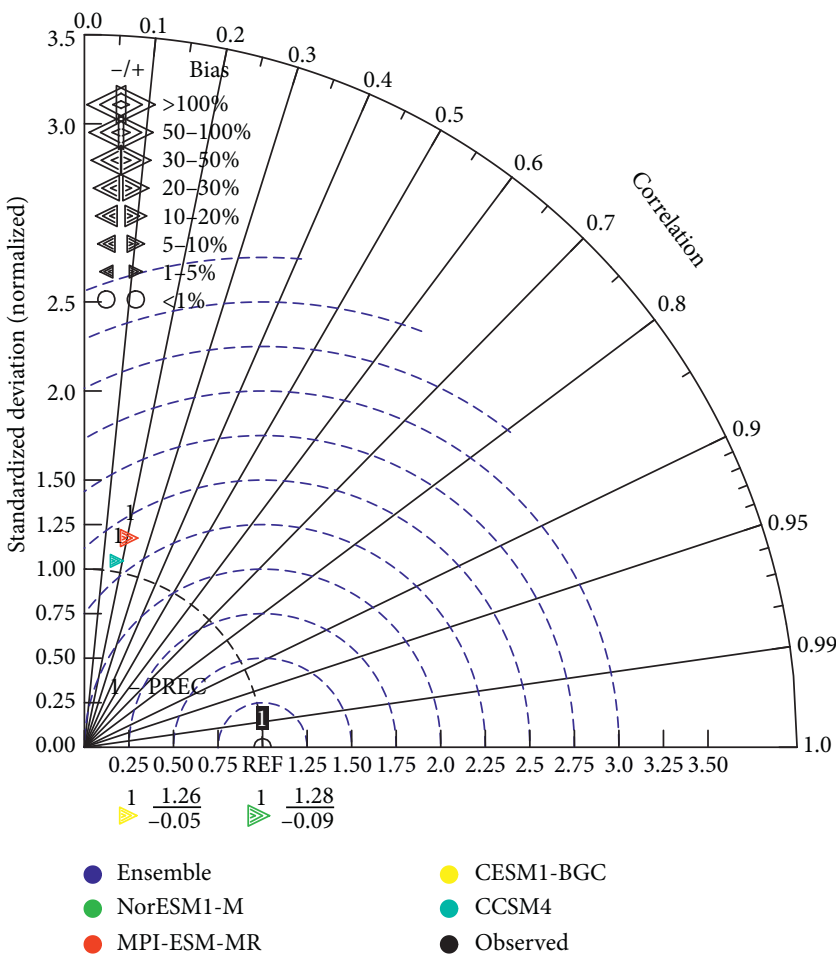

(c)

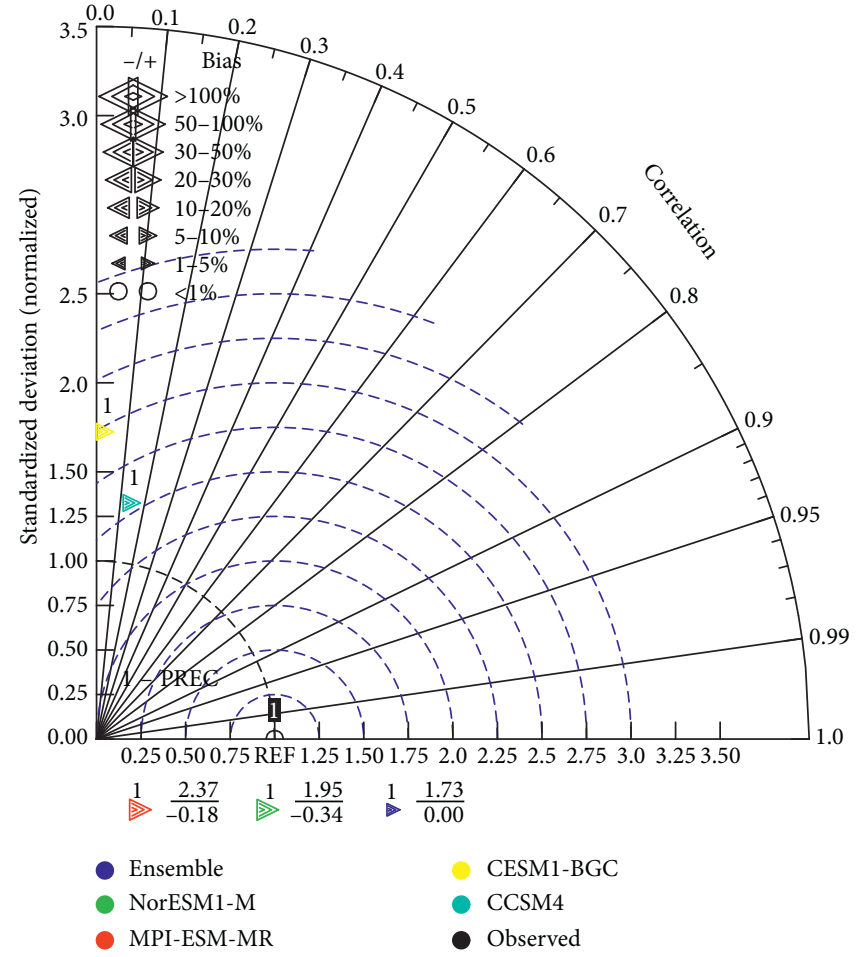

(b)

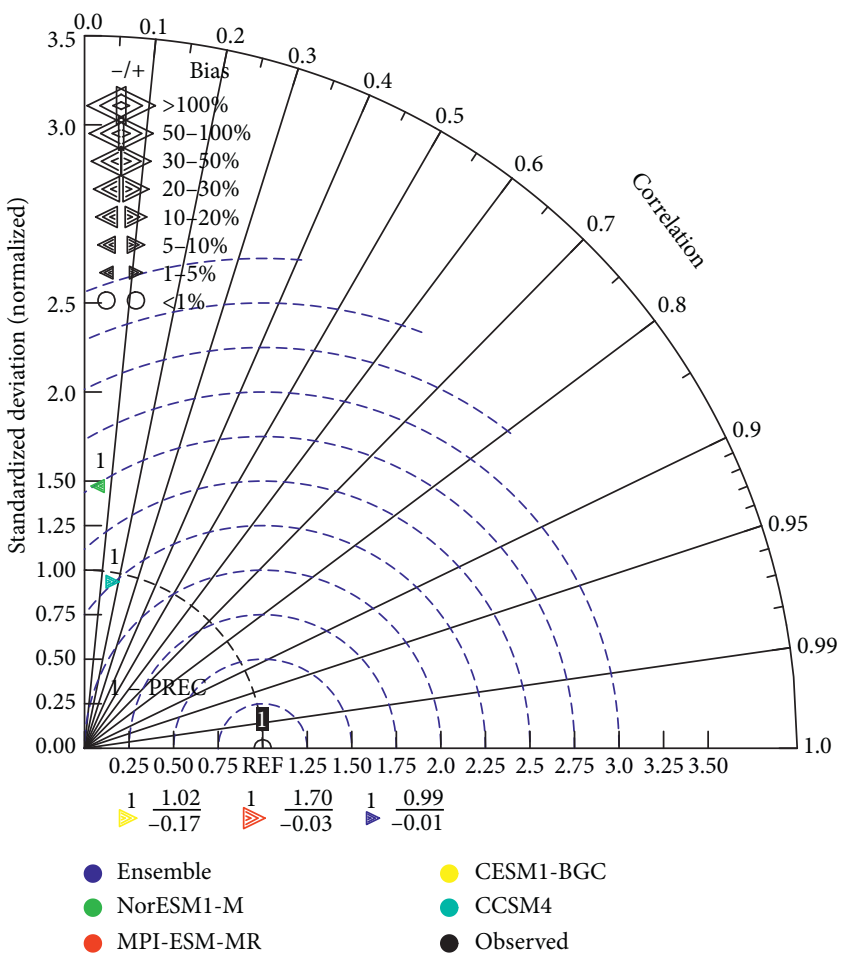

(d)

FIGURE 11: Taylor diagram for the Soudano-Sahel showing the normalized standard deviation, the correlation, and the RMSE representing the variability, pattern, and errors, respectively, within the models and the reference data: DJF (a); MAM (b); JJA (c); SON (d). 


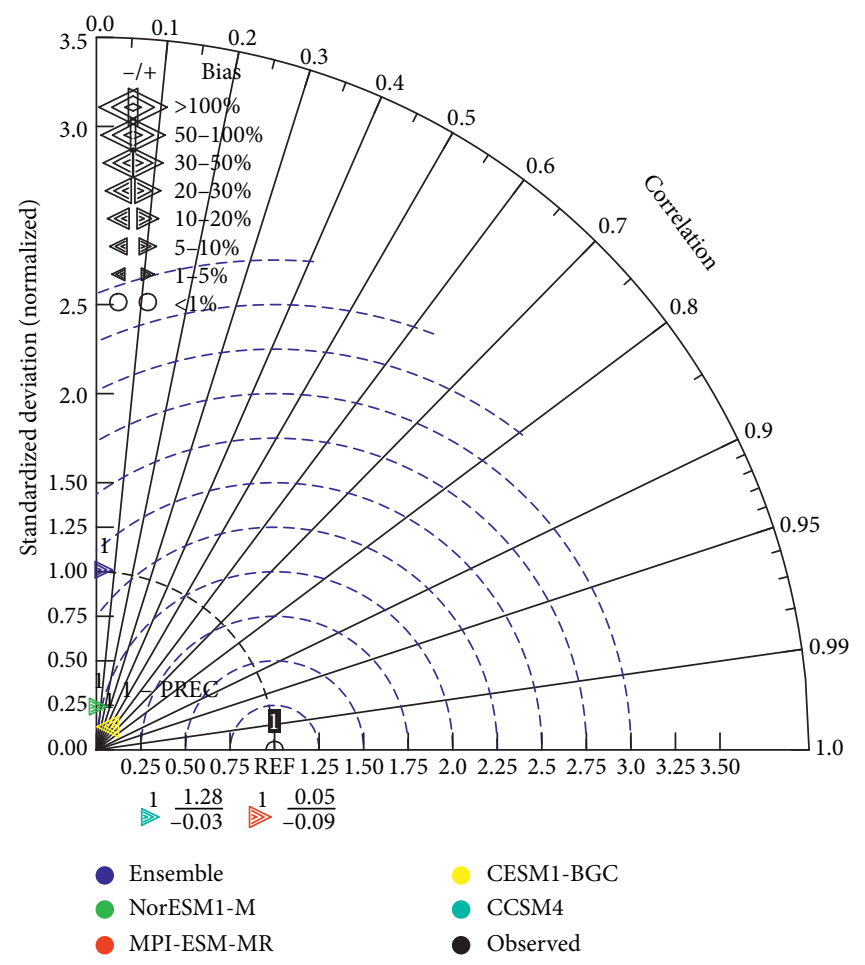

(a)

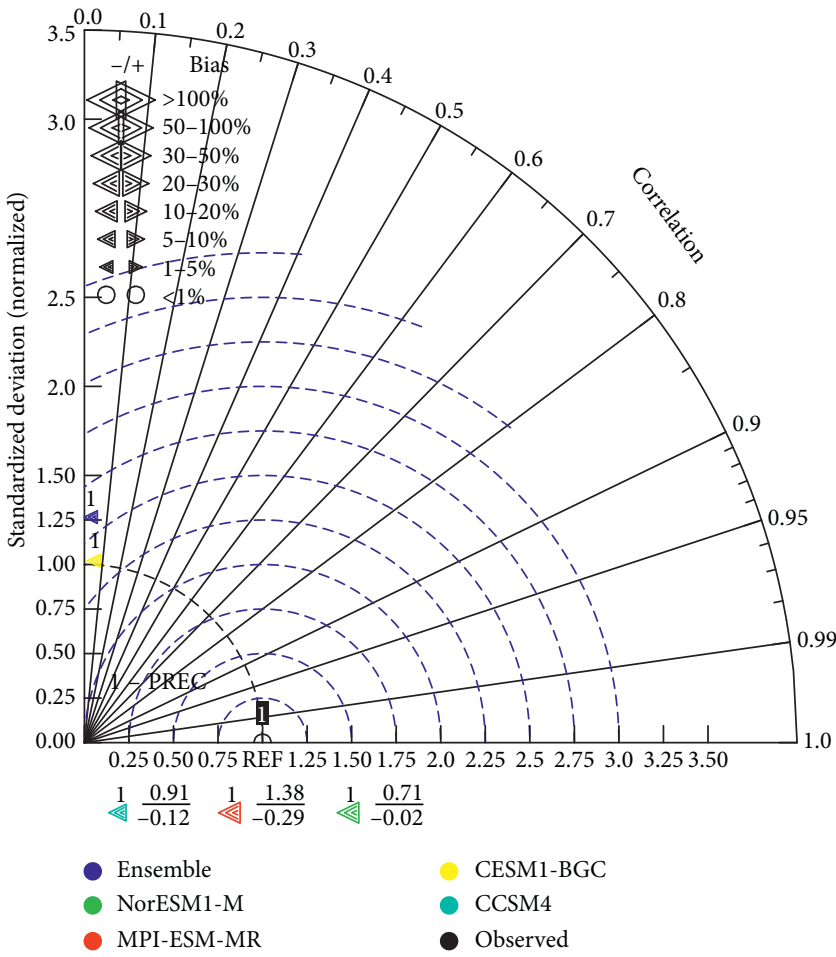

(c)

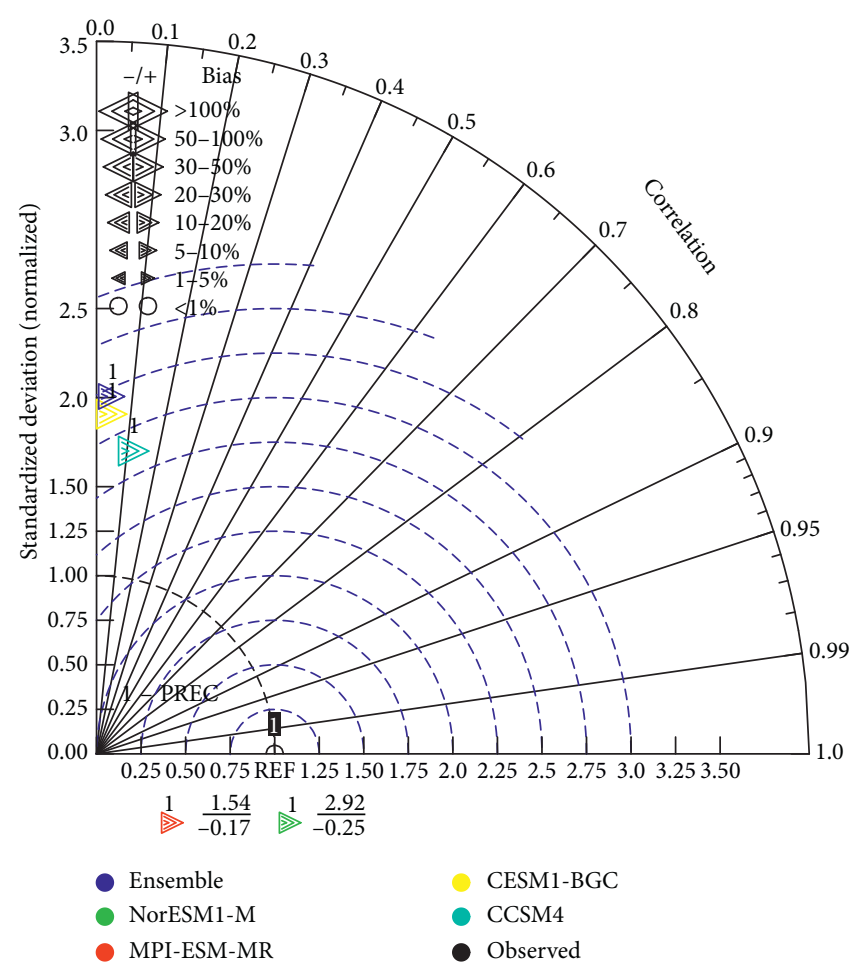

(b)

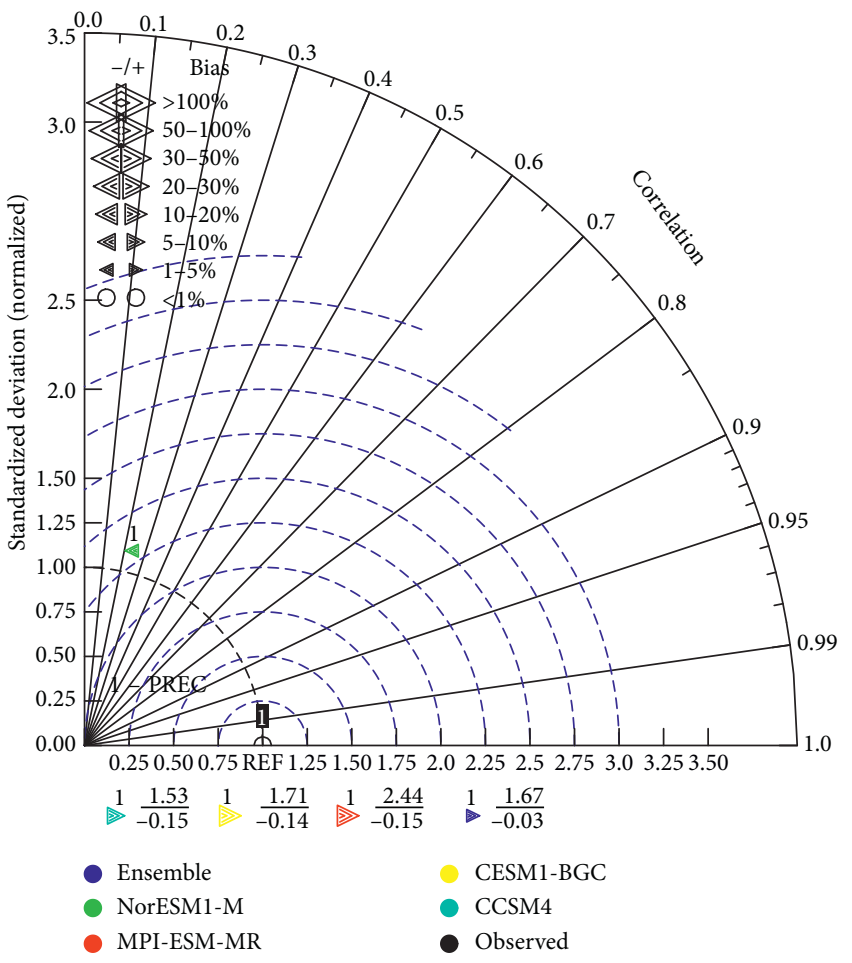

(d)

FIGURE 12: Taylor diagram for the Sahel showing the normalized standard deviation, the correlation, and the RMSE representing the variability, pattern, and errors, respectively, within the models and the reference data: DJF (a); MAM (b); JJA (c); SON (d). 
observed variability with the EM $(\sigma=0.7)$ and the CCSM4 $(\sigma=0.7)$ simulating variability close to the observed. In fall, the CCSM4 $(\sigma=1.6)$ and MPI-ESM-MR $(\sigma=1.7)$ simulate high variability with the CESM1-BGC $(\sigma=1.4)$ and the EM $(\sigma=1.1)$ simulating variability close to the observed variability. Relatively, the EM and the CCSM4 simulate the observed variability over the Guinea Coast fairly well.

(3) The Soudano-Sahel. The temporal correlation for all the models and for all the seasons (Figure 11) is less than 0.4. In the winter season, all models simulate variability less than 1 with the EM $(\sigma=0.6)$ simulating variability close to the observed precipitation. The MPI-ESM-MR $(\sigma=2.4)$, NorESM1-M $(\sigma=2.0)$, CESM1-BGC $(\sigma=1.8)$, and EM $(\sigma=1.7)$ simulate relatively high variability in spring. However, the CCSM4 $(\sigma=1.4)$ simulates variability close to the observed. In summer, the CCSM4 $(\sigma=1.1)$ and the MPIESM-MR $(\sigma=1.2)$ simulate variability close to the observed. The CESM1-BGC $(\sigma=1.3)$ and NorESM1-M $(\sigma=1.3)$ simulate variability close to the observed with negative correlations, whereas a variability of 1.7 is recorded for the EM. The MPI-ESM-MR $(\sigma=1.7)$ and NorESM1-M $(\sigma=1.5)$ have high variability in fall with negative correlations for the CESM1-BGC $(\sigma=1.0)$ and the EM $(\sigma=1.0)$. However, the CCSM4 $(\sigma=1.0)$ has variability close to the observed. Again, the CCSM4 does relatively well in simulating the observed variability over the Soudano-Sahel.

(4) The Sahel. The correlation for all the models in the four seasons over the Sahel (Figure 12) is less than 0.4. In winter, the EM $(\sigma=1.0)$ simulates variability close to the observed, while the rest of the models simulate variability less than the observed. The CCSM4 $(\sigma=1.3)$ also simulates variability close to the observed but with a negative correlation. In spring, the NorESM1-M $(\sigma=2.9)$, CCSM4 $(\sigma=1.7)$, CESM1BGC $(\sigma=1.9)$, and MPI-ESM-MR $(\sigma=1.5)$ including the EM $(\sigma=2.1)$ simulate high variability. In summer, the CESM1BGC $(\sigma=1.0)$ and EM $(\sigma=1.3)$ simulate variability approximate to the observed. The CCSM4 $(\sigma=0.9)$, the MPI-ESM-MR $(\sigma=1.4)$, and the NorESM1-M $(\sigma=0.7)$ have negative correlations. In fall, the MPI-ESM-MR $(\sigma=2.4)$, CCSM4 $(\sigma=1.5)$, CESM1-BGC $(\sigma=1.7)$, and EM $(\sigma=1.7)$ simulate relatively high variability with the NorESM1-M simulating variability close to the observed variability. The variability for each season in the Sahel is simulated well by different models.

Precipitation varies highly spatially, from one region to another over the basin. The models' inability to simulate the observed pattern (low correlation) could be a result of the varying nature of spatial precipitation. The models (GCMs) are unable to capture this pattern probably because of the coarse resolutions and hence their inability to capture the subgrid features, such as orography, and its accompanied precipitation and convective clouds, that influence the varying nature of precipitation over the region (e.g., $[57,62,63]$ ). Generally, models evaluated in this study underestimate the observed variability in winter. Precipitation does not vary much spatially in winter over the basin due to the fact that the entire basin is under the influence of the dry northeasterly trade winds, and the models seem to strengthen this general dryness across the basin by reproducing a smaller variability compared to the observed. Although the models are unable to simulate the observed pattern, the observed variability is simulated relatively well by the CCSM4 and the EM over the basin and the three belts. In the case of the EM, this study is consistent with previous studies (e.g., $[19,20]$ ) that suggest better performances for EMs.

3.3.4. Interannual Variability of Precipitation. In the assessment of the interannual variability (Figure 13), the ability of the models to capture the observed deviation from the climatological mean of the period of study (1950-2004) is analyzed, for the basin and also for the three belts. The deviation shows the magnitude of how much high or low a particular year's total precipitation is from the period mean of the annual total precipitation.

Over the entire basin and the three belts, the CCSM4 does relatively well in reproducing the observed variability. The CCSM4 is able to simulate the positive or negative deviations better than the other models. All the other models generally had difficulty in simulating the observed year-toyear variability. Often, they simulate opposite deviations as compared to the observed data. This confirms the low correlations between the observed and the simulated precipitation on the seasonal scale.

\section{Conclusion}

This study assesses the performance of 18 GCMs in simulating present-day climatology (1950-2004) precipitation over the Volta Basin including the three belts: the Guinea Coast, the Soudano-Sahel, and the Sahel. The analyses were done on annual, seasonal, and monthly timescales.

First, the models' ability to simulate the spatial distribution of precipitation over the Volta Basin was investigated by analyzing the biases in climatological mean of the annual total precipitation. Six models (MIROC5, CSIRO-Mk3.6.0, MIROC-ESM, CNRM-CM5, CanESM2, and EC-EARTH) overestimate the observed precipitation over most parts of the basin, while six other models (MRI-CGCM3, INMCM4, HadGEM2-CC, IPSL-CM5A-MR, HadGEM2-AO, and CMCC-CM) underestimate the observed climatological mean of the annual total precipitation. Models such as the CESM1-BGC, CCSM4, NorESM1-M, MPI-ESM-MR, and $\mathrm{EM}$ of all the eighteen models perform relatively well in the simulation of the annual precipitation over the Volta Basin with small biases over most parts of the basin. The four models, together with the EM, were then used to assess the regional differences in interannual, seasonal, and monthly precipitation temporal patterns.

For the seasonal analysis, the three statistics: the correlation $(r)$, the standard deviation $(\sigma)$, and the root-meansquare error (RMSE), are used to evaluate the temporal pattern, variability, and error in the models. The models (CESM1-BGC, CCSM4, NorESM1-M, and MPI-ESM-MR) were assessed for the winter (DJF), spring (MAM), summer (JJA), and fall (SON) seasons for the Volta Basin and the 


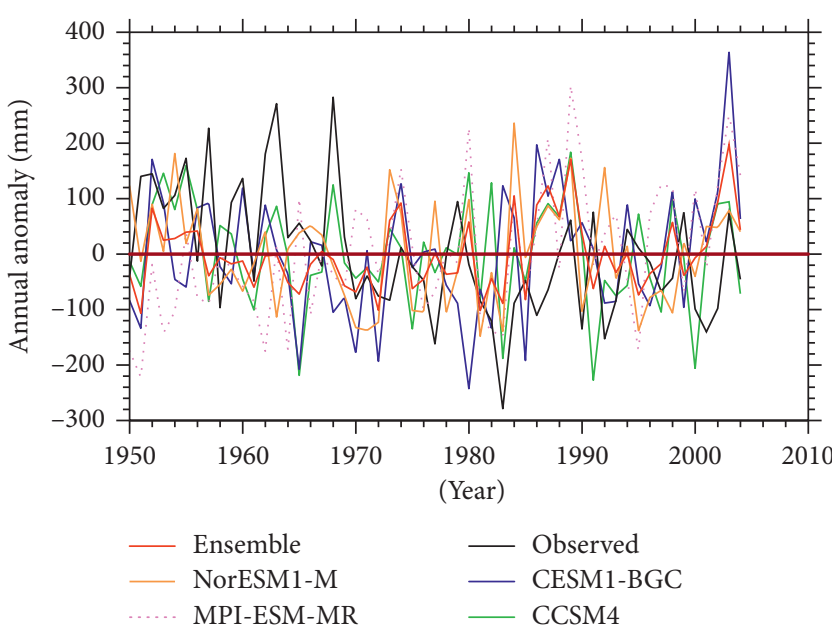

(a)

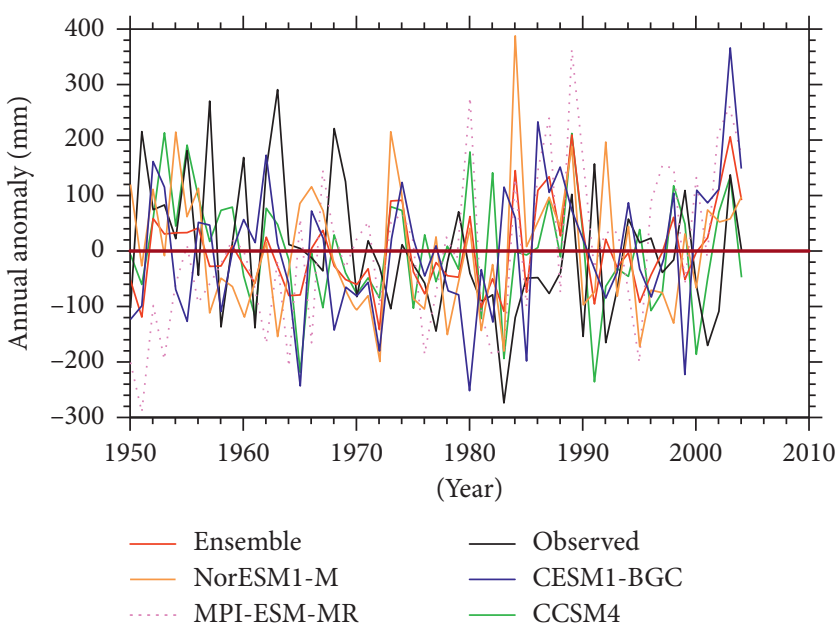

(c)

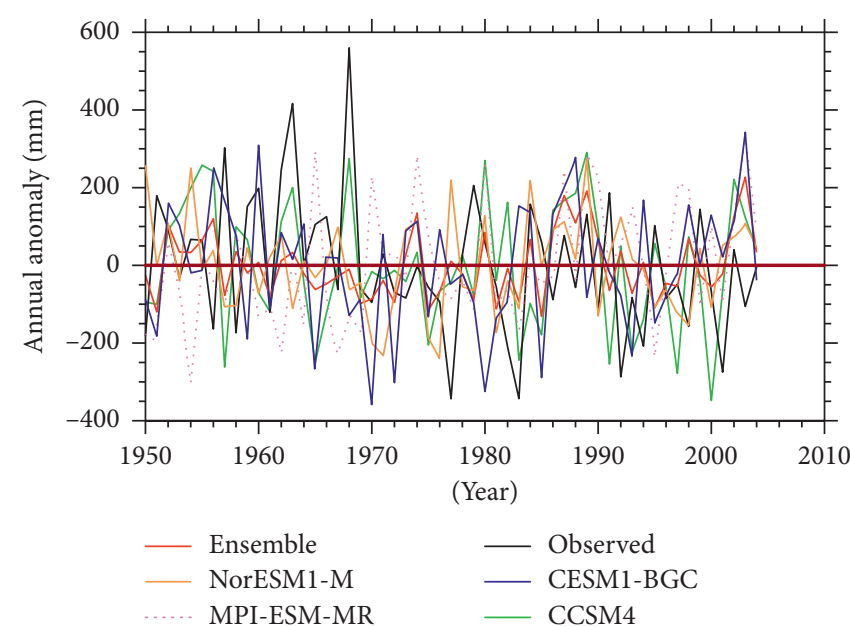

(b)

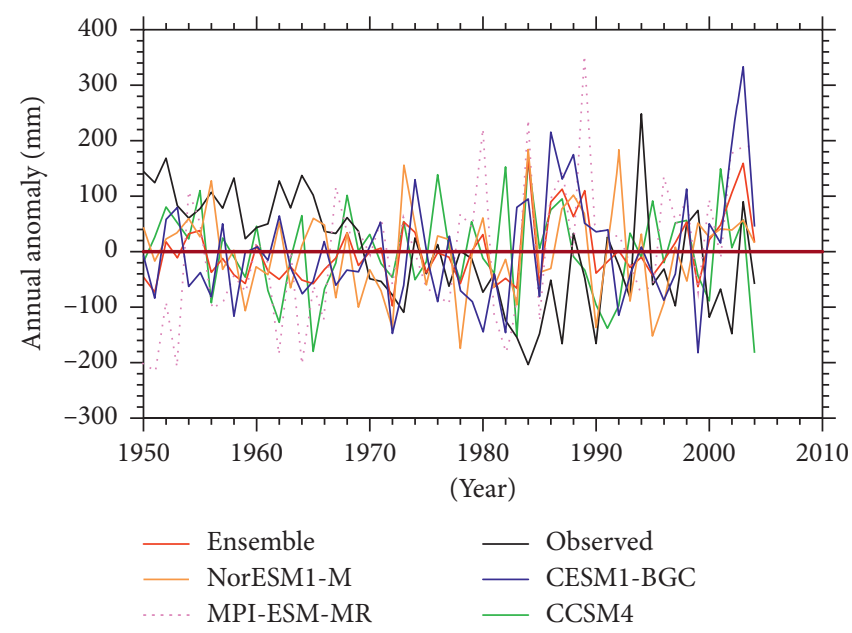

(d)

Figure 13: The series of interannual variability over the Volta Basin (a), the Guinea Coast (b), the Soudano-Sahel (c), and the Sahel (d). The anomaly is calculated using the 1950-2004 period mean.

three belts. Overall, all the models scored relatively low on the correlation coefficient $(<0.5)$ but with varying standard deviations (1.0-7.3). The low correlations indicate that all the models had difficulty in simulating the observed seasonal precipitation pattern over the entire region and the three belts. In spite of all the models' inability to simulate the precipitation pattern, the CCSM4 does relatively well in simulating the observed variability over the Volta Basin, the Guinea Coast, and the Soudano-Sahel.

In the trend analysis, the Mann-Kendall test and the Pettitt test were used to analyze the seasonal total precipitation trend and the change point over the entire basin and the three belts for the dry and rainy seasons. Over the Volta Basin, the Soudano-Sahel, and the Sahel, the CCSM4 and the NorESM1-M are able to reproduce the observed trend best for the dry and rainy seasons, respectively. Over the Guinea Coast, the MPI-ESM-MR best reproduces the observed trend in the major and minor dry seasons, while the NorESM1-M and the CCSM4 reproduce the trend in the major rainy season and minor rainy season, respectively. The performance of the EM in the seasonal precipitation trend is relatively poor.

In the case of the annual cycles, the ability of the models to simulate the bimodal precipitation pattern over the Guinea Coast and the unimodal pattern over the SoudanoSahel, Sahel, and the whole basin is presented. The climatological mean of the monthly totals of the models was calculated and compared to the observed. In the Guinea Coast, all the four models (CESM1-BGC, CCSM4, NorESM1-M, and MPI-ESM-MR) are unable to reproduce the bimodal pattern in June for the major rainy season and September for the minor rainy season, respectively. Over the Soudano-Sahel, all the models are able to simulate the maximum precipitation in August, but the MPI-ESM-MR overestimates the observed maximum precipitation. The NorESM1-M (214.63 mm), CESM1-BGC $(216.74 \mathrm{~mm})$, CCSM4 $(224.34 \mathrm{~mm})$, and models' ensemble mean $(220.39 \mathrm{~mm})$ are able to simulate the maximum precipitation close to the observed $(216.56 \mathrm{~mm})$. In the Sahel, all the models underestimate the maximum precipitation 
(209.49 mm). The MPI-ESM-MR $(211.48 \mathrm{~mm})$ is able to simulate well the maximum observed precipitation.

Generally, models' performances are dependent on simulation of features that influence the distribution of precipitation. Course grid size of GCMs remains the limitation in simulating some observed climatic variables. Clearly, one model could not be singled out to be the best one for all the regions and also for all timescales. Notwithstanding, the CCSM4 does relatively well in simulating the observed precipitation over the basin and the three belts for almost all the timescales used in this analysis.

Our results provide insight into CMIP5 GCMs that can be used as input data in relation to precipitation for impact studies or to drive an RCM over the Volta Basin. Future projection of precipitation for the four models over the Volta Basin needs to be considered to help in adequate planning against any future changes in precipitation over the basin.

\section{Conflicts of Interest}

The authors declare that they have no conflicts of interest.

\section{Acknowledgments}

The authors are thankful to the German Climate Computing Centre (DKRZ) for providing access to the global climate models used in this study. The authors appreciate the contributions of the Global Precipitation Climatology Centre (GPCC) for the observed data used in the research. The authors also acknowledge all individuals and institutions that made the various precipitation data sets available on the Internet. The authors also thank the reviewers for their helpful comments.

\section{References}

[1] P. Roudier, B. Sultan, P. Quirion, and A. Berg, "The impact of future climate change on West African crop yields: what does the recent literature say?," Global Environmental Change, vol. 21, no. 3, pp. 1073-1083, 2011.

[2] B. Sultan, C. Baron, M. Dingkuhn, B. Sarr, and S. Janicot, "Agricultural impacts of large-scale variability of the West African monsoon," Agricultural and Forest Meteorology, vol. 128, no. 1-2, pp. 93-110, 2005.

[3] J. Sheffield, E. F. Wood, and M. L. Roderick, "Little change in global drought over the past 60 years," Nature, vol. 491, no. 7424, pp. 435-438, 2012.

[4] S. E. Nicholson, C. J. Tucker, and M. Ba, "Desertification, drought, and surface vegetation: an example from the West African Sahel," Bulletin of the American Meteorological Society, vol. 79, no. 5, pp. 815-829, 1998.

[5] A. Tarhule, "Damaging rainfall and flooding: the other Sahel hazards," Climatic Change, vol. 72, no. 3, pp. 355-377, 2005.

[6] N. K. Karley, "Flooding and physical planning in urban areas in West Africa: situational analysis of Accra, Ghana," Theoretical and Empirical Researches in Urban Management, vol. 4, no. 13, pp. 25-41, 2009.

[7] N. van de Giesen, M. Andreini, A. van Edig, and P. Vlek, Competition for Water Resources of the Volta Basin, IAHS Publication, Wallingford, UK, 2001.

[8] M. Andreini, P. Vlek, and N. Van De Giesen, "Water sharing in the Volta Basin," in FRIEND 2002-Regional Hydrology:
Bridging the Gap between Research and Practice, no. 274, pp. 329-336, IAHS Publication, Wallingford, UK, 2002.

[9] T. Annor, Potential impacts of climate variability and change on hydrology and water resources over the Volta Basin, Ph.D. thesis, Department of Meteorology and Climate Science, The Federal University of Technology, Akure, Nigeria, 2015.

[10] P. K. Adom, W. Bekoe, and S. K. K. Akoena, "Modelling aggregate domestic electricity demand in Ghana: an autoregressive distributed lag bounds cointegration approach," Energy Policy, vol. 42, pp. 530-537, 2012.

[11] B. Barry, E. Obuobie, M. Andreini, W. Andah, and M. Pluquet, Comprehensive Assessment of Water Management in Agriculture (Comparative Study of River Basin Development and Management), International Water Management Institute, Colombo, Sri Lanka, 2005.

[12] M. B. Sylla, A. T. Gaye, J. S. Pal, G. S. Jenkins, and X. Q. Bi, "High-resolution simulations of West African climate using regional climate model $\left(\operatorname{RegCM}{ }_{3}\right)$ with different lateral boundary conditions," Theoretical and Applied Climatology, vol. 98, no. 3-4, pp. 293-314, 2009.

[13] M. Andreini, N. van de Giesen, A. van Edig, M. Fosu, and W. Andah, "Volta Basin water balance," ZEF-Discussion Papers On Development Policy No. 21, Center for Development Research, Bonn, Germany, 2000.

[14] J. Houghton, Y. Ding, D. Griggs et al., "The climate change contribution of Working Group I to the Third Assessment Report of the Intergovemmental Panel on Climate Change," in Proceedings of the IPCC 2001: Climate Change 2001, vol. 159, Wembley, UK, September 2001.

[15] M. L. Parry, O. F. Canziani, J. P. Palutikof, P. J. van der Linden, and C. E. Hanson, "Contribution of Working Group II to the Fourth Assessment Report of the Intergovernmental Panel on Climate Change," in Proceedings of the IPCC 2007: Climate Change 2007: Impacts, Adaptation and Vulnerability, Geneva, Switzerland, 2007.

[16] T. Stocker, D. Qin, G. Plattner et al., "Contribution of Working Group I to the Fifth Assessment Report of the Intergovernmental Panel on Climate Change," in Proceedings of the IPCC 2013: Climate Change 2013: The Physical Science Basis, Stockholm, Sweden, September 2013.

[17] R. Neumann, G. Jung, P. Laux, and H. Kunstmann, "Climate trends of temperature, precipitation and river discharge in the Volta Basin of West Africa," International Journal of River Basin Management, vol. 5, no. 1, pp. 17-30, 2007.

[18] H. Kunstmann and G. Jung, Impact of Regional Climate Change on Water Availability in the Volta Basin of West Africa, IAHS Publication, Wallingford, UK, 2005.

[19] A. Mehran, A. AghaKouchak, and T. J. Phillips, "Evaluation of CMIP5 continental precipitation simulations relative to satellite-based gauge-adjusted observations," Journal of Geophysical Research: Atmospheres, vol. 119, no. 4, pp. 1695-1707, 2014.

[20] S. Kumar, V. Merwade, J. L. Kinter III, and D. Niyogi, "Evaluation of temperature and precipitation trends and longterm persistence in CMIP5 twentieth-century climate simulations," Journal of Climate, vol. 26, no. 12, pp. 4168-4185, 2013.

[21] D. E. Rupp, J. T. Abatzoglou, K. C. Hegewisch, and P. W. Mote, "Evaluation of CMIP5 20th century climate simulations for the Pacific Northwest USA," Journal of Geophysical Research: Atmospheres, vol. 118, no. 19, 2013.

[22] J. Cattiaux, H. Douville, and Y. Peings, "European temperatures in CMIP5: origins of present-day biases and future 
uncertainties," Climate Dynamics, vol. 41, no. 11-12, pp. 2889-2907, 2013.

[23] J. Perez, M. Menendez, F. J. Mendez, and I. J. Losada, "Evaluating the performance of CMIP3 and CMIP5 global climate models over the north-east Atlantic region," Climate Dynamics, vol. 43, no. 9-10, pp. 2663-2680, 2014.

[24] C. Miao, Q. Duan, Q. Sun et al., "Assessment of CMIP5 climate models and projected temperature changes over Northern Eurasia," Environmental Research Letters, vol. 9, no. 5, article 055007, 2014.

[25] J. Zhang, L. Li, T. Zhou, and X. Xin, "Evaluation of spring persistent rainfall over East Asia in CMIP3/CMIP5 AGCM simulations," Advances in Atmospheric Sciences, vol. 30, no. 6, pp. 1587-1600, 2013.

[26] R. Allen, J. Norris, and M. Wild, "Evaluation of multidecadal variability in CMIP5 surface solar radiation and inferred underestimation of aerosol direct effects over Europe, China, Japan, and India," Journal of Geophysical Research: Atmospheres, vol. 118, no. 12, pp. 6311-6336, 2013.

[27] D.-Q. Huang, J. Zhu, Y.-C. Zhang, and A.-N. Huang, "Uncertainties on the simulated summer precipitation over Eastern China from the CMIP5 models," Journal of Geophysical Research: Atmospheres, vol. 118, no. 16, pp. 90359047, 2013.

[28] J. H. Siew, F. T. Tangang, and L. Juneng, "Evaluation of CMIP5 coupled atmosphere-ocean general circulation models and projection of the Southeast Asian winter monsoon in the 21st century," International Journal of Climatology, vol. 34, no. 9, pp. 2872-2884, 2014.

[29] G. Nikulin, C. Jones, F. Giorgi et al., "Precipitation climatology in an ensemble of CORDEX-Africa regional climate simulations," Journal of Climate, vol. 25, no. 18, pp. 60576078, 2012.

[30] P. M. Nikiema, M. B. Sylla, K. Ogunjobi, I. Kebe, P. Gibba, and F. Giorgi, "Multi-model CMIP5 and CORDEX simulations of historical summer temperature and precipitation variabilities over West Africa," International Journal of Climatology, vol. 37, no. 5, pp. 2438-2450, 2017.

[31] T. Annor, B. Lamptey, S. Wagner et al., "High-resolution long-term WRF climate simulations over Volta Basin. Part 1: validation analysis for temperature and precipitation," Theoretical and Applied Climatology, vol. 133, no. 3-4, pp. 829849, 2017.

[32] R. Y. K. Agyeman, T. Annor, B. Lamptey, E. Quansah, J. Agyekum, and S. A. Tieku, "Optimal physics parameterization scheme combination of the weather research and forecasting model for seasonal precipitation simulation over Ghana," Advances in Meteorology, vol. 2017, Article ID 7505321, 15 pages, 2017.

[33] F. Aziz and E. Obuobie, "Trend analysis in observed and projected precipitation and mean temperature over the Black Volta Basin, West Africa," International Journal of Current Engineering and Technology, vol. 7, no. 4, 2017.

[34] F. Giorgi and W. J. Gutowski, "Regional dynamical downscaling and the CORDEX initiative," Annual Review of Environment and Resources, vol. 40, no. 1, pp. 467-490, 2015.

[35] U. Schneider, T. Fuchs, A. Meyer-Christoffer, and B. Rudolf, Global Precipitation Analysis Products of the GPCC, Vol. 112, Global Precipitation Climatology Centre (GPCC), DWD, Internet Publikation, 2008.

[36] B. Andreas, P. Finger, A. Peter Meyer-Christoffer, B. Rudolf, and M. Ziese, "GPCC Full Data Reanalysis Version 7.0 at 0.5: monthly land-surface precipitation from rain-gauges built on GTS-based and historic data," 2011.
[37] S. E. Nicholson, B. Some, J. McCollum et al., "Validation of TRMM and other rainfall estimates with a high-density gauge dataset for West Africa. Part I: validation of GPCC rainfall product and pre-TRMM satellite and blended products," Journal of Applied Meteorology, vol. 42, no. 10, pp. 1337-1354, 2003.

[38] H. Paeth, A. H. Fink, S. Pohle, F. Keis, H. Mächel, and C. Samimi, "Meteorological characteristics and potential causes of the 2007 flood in sub-Saharan Africa," International Journal of Climatology, vol. 31, no. 13, pp. 1908-1926, 2011.

[39] A. Gruber, X. Su, M. Kanamitsu, and J. Schemm, "The comparison of two merged rain gauge-satellite precipitation datasets," Bulletin of the American Meteorological Society, vol. 81, no. 11, pp. 2631-2644, 2000.

[40] G. Flato, J. Marotzke, B. Abiodun et al., "Evaluation of climate models. Contribution of Working Group I to the Fifth Assessment Report of the Intergovernmental Panel on Climate Change," in Proceedings of the IPCC 2013: Climate Change: The Physical Science Basis, vol. 5, pp. 741-866, Stockholm, Sweden, September 2013.

[41] K. E. Taylor, R. J. Stouffer, and G. A. Meehl, "A summary of the CMIP5 experiment design,” PCDMI Report, vol. 33, 2009.

[42] K. E. Taylor, R. J. Stouffer, and G. A. Meehl, "An overview of CMIP5 and the experiment design," Bulletin of the American Meteorological Society, vol. 93, no. 4, p. 485, 2012.

[43] P. W. Jones, A User's Guide for SCRIP: A Spherical Coordinate Remapping and Interpolation Package, Los Alamos National Laboratory, Los Alamos, NM, USA, 1997.

[44] P. W. Jones, "First- and second-order conservative remapping schemes for grids in spherical coordinates," Monthly Weather Review, vol. 127, no. 9, pp. 2204-2210, 1999.

[45] Y. Fujihara, Y. Yamamoto, Y. Tsujimoto, J.-I. Sakagami et al., "Discharge simulation in a data-scarce basin using reanalysis and global precipitation data: a case study of the White Volta Basin," Journal of Water Resource and Protection, vol. 6, no. 14, p. 1316, 2014.

[46] H. B. Mann, "Nonparametric tests against trend," Econometrica: Journal of the Econometric Society, vol. 13, no. 3, pp. 245-259, 1945.

[47] M. Kendall, "Rank correlation methods," Technical Report, Griffin \& Co, London, UK, 1975.

[48] A. Pettitt, "A non-parametric approach to the change-point problem," Applied Statistics, vol. 28, no. 2, pp. 126-135, 1979.

[49] R. O. Gilbert, "6.5 Sen's nonparametric estimator of slope," in Statistical Methods for Environmental Pollution Monitoring, pp. 217-219, John Wiley and Sons, Hoboken, NJ, USA, 1987.

[50] S. Yue, P. Pilon, and G. Cavadias, "Power of the MannKendall and Spearman's rho tests for detecting monotonic trends in hydrological series," Journal of Hydrology, vol. 259, no. 1-4, pp. 254-271, 2002.

[51] R. Modarres and V. d. P. R. da Silva, "Rainfall trends in arid and semi-arid regions of Iran," Journal of Arid Environments, vol. 70, no. 2, pp. 344-355, 2007.

[52] S. E. Nicholson, "A revised picture of the structure of the "monsoon" and land ITCZ over West Africa," Climate Dynamics, vol. 32, no. 7-8, pp. 1155-1171, 2009.

[53] S. Janicot and B. Sultan, "Intra-seasonal modulation of convection in the West African monsoon," Geophysical Research Letters, vol. 28, no. 3, pp. 523-526, 2001.

[54] Z.-Z. Hu, B. Huang, Y.-H. Tseng et al., "Does vertical temperature gradient of the atmosphere matter for El Niño development?," Climate Dynamics, vol. 48, no. 5-6, pp. 1413-1429, 2016. 
[55] D. J. Seidel, Q. Fu, W. J. Randel, and T. J. Reichler, "Widening of the tropical belt in a changing climate," Nature Geoscience, vol. 1, no. 1, pp. 21-24, 2008.

[56] D. A. Randall, R. A. Wood, S. Bony et al., "Climate models and their evaluation. Contribution of Working Group I to the Fourth Assessment Report of the IPCC (FAR)," in Proceedings of the IPCC 2007: Climate change 2007: The Physical Science Basis, pp. 589-662, Cambridge University Press, Geneva, Switzerland, 2007.

[57] R. L. Wilby and T. Wigley, "Downscaling general circulation model output: a review of methods and limitations," Progress in Physical Geography, vol. 21, no. 4, pp. 530-548, 1997.

[58] P. Laux, H. Kunstmann, and A. Bárdossy, "Predicting the regional onset of the rainy season in West Africa," International Journal of Climatology, vol. 28, no. 3, pp. 329-342, 2008.

[59] K. I. Mohr, "Interannual, monthly, and regional variability in the wet season diurnal cycle of precipitation in sub-Saharan Africa," Journal of Climate, vol. 17, no. 12, pp. 2441-2453, 2004.

[60] B. Sultan and S. Janicot, "Abrupt shift of the ITCZ over West Africa and intra-seasonal variability," Geophysical Research Letters, vol. 27, no. 20, pp. 3353-3356, 2000.

[61] S. E. Nicholson and J. P. Grist, "The seasonal evolution of the atmospheric circulation over West Africa and Equatorial Africa," Journal of Climate, vol. 16, no. 7, pp. 1013-1030, 2003.

[62] T. Wigley, P. Jones, K. Briffa, and G. Smith, "Obtaining subgrid-scale information from coarse-resolution general circulation model output," Journal of Geophysical Research: Atmospheres, vol. 95, no. 2, pp. 1943-1953, 1990.

[63] F. Giorgi, "Simulation of regional climate using a limited area model nested in a general circulation model," Journal of Climate, vol. 3, no. 9, pp. 941-963, 1990.

[64] M. New, B. Hewitson, D. B. Stephenson et al., "Evidence of trends in daily climate extremes over southern and west Africa," Journal of Geophysical Research: Atmospheres, vol. 111, no. 14, 2006.

[65] A. Giannini, R. Saravanan, and P. Chang, "Oceanic forcing of Sahel rainfall on interannual to interdecadal time scales," Science, vol. 302, no. 5647, pp. 1027-1030, 2003.

[66] J. G. Charney, "Dynamics of deserts and drought in the Sahel," Quarterly Journal of the Royal Meteorological Society, vol. 101, no. 428, pp. 193-202, 1975.

[67] L. M. Druyan, "Studies of 21st-century precipitation trends over West Africa," International Journal of Climatology, vol. 31, no. 10, pp. 1415-1424, 2011.

[68] K. E. Taylor, "Summarizing multiple aspects of model performance in a single diagram," Journal of Geophysical Research: Atmospheres, vol. 106, no. 7, pp. 7183-7192, 2001. 

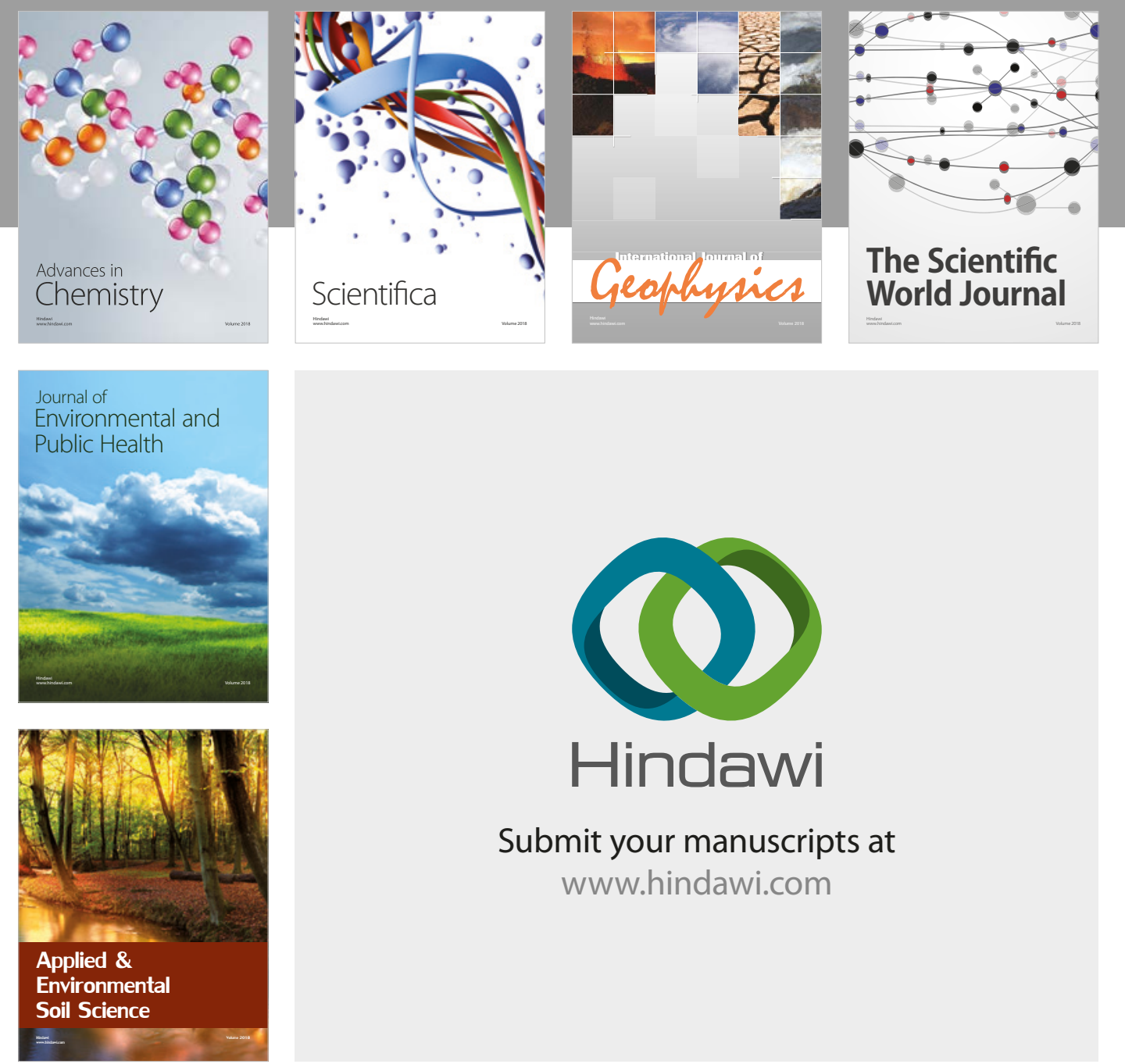

The Scientific

\section{World Journal}
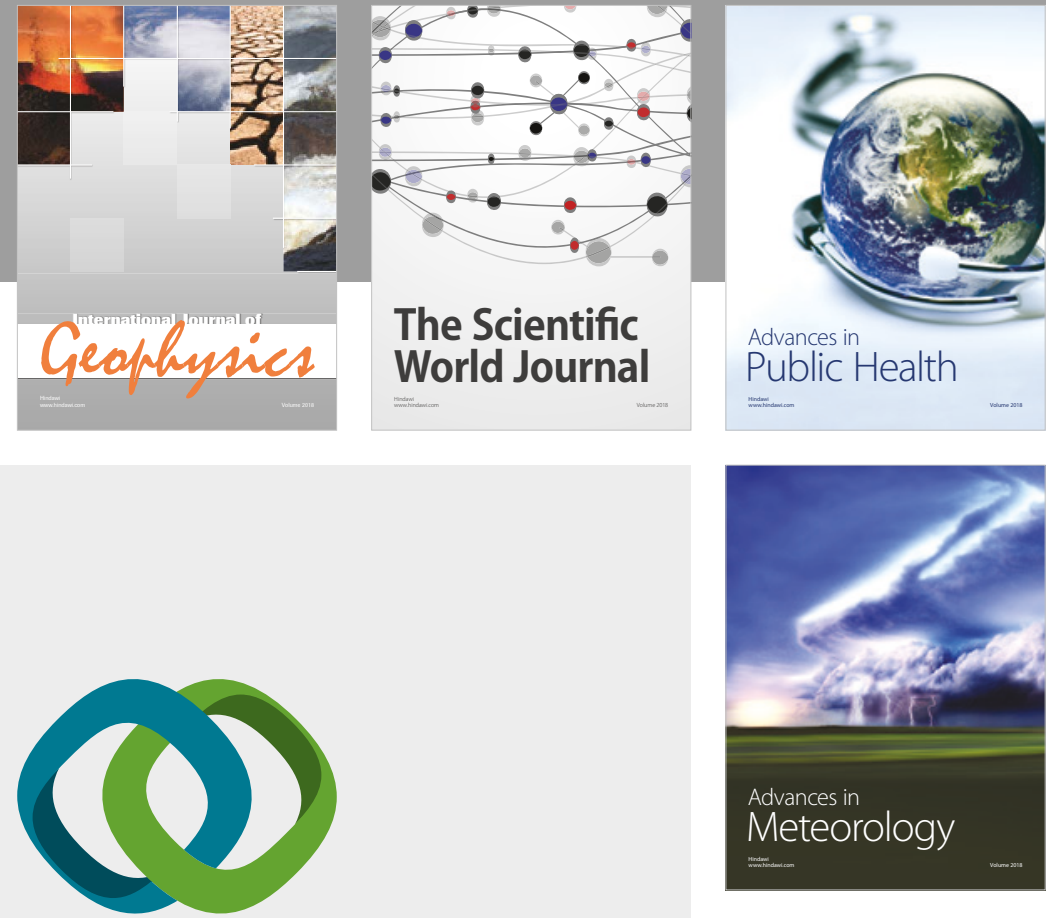

Advan

Public Health

\section{Hindawi}

Submit your manuscripts at

www.hindawi.com
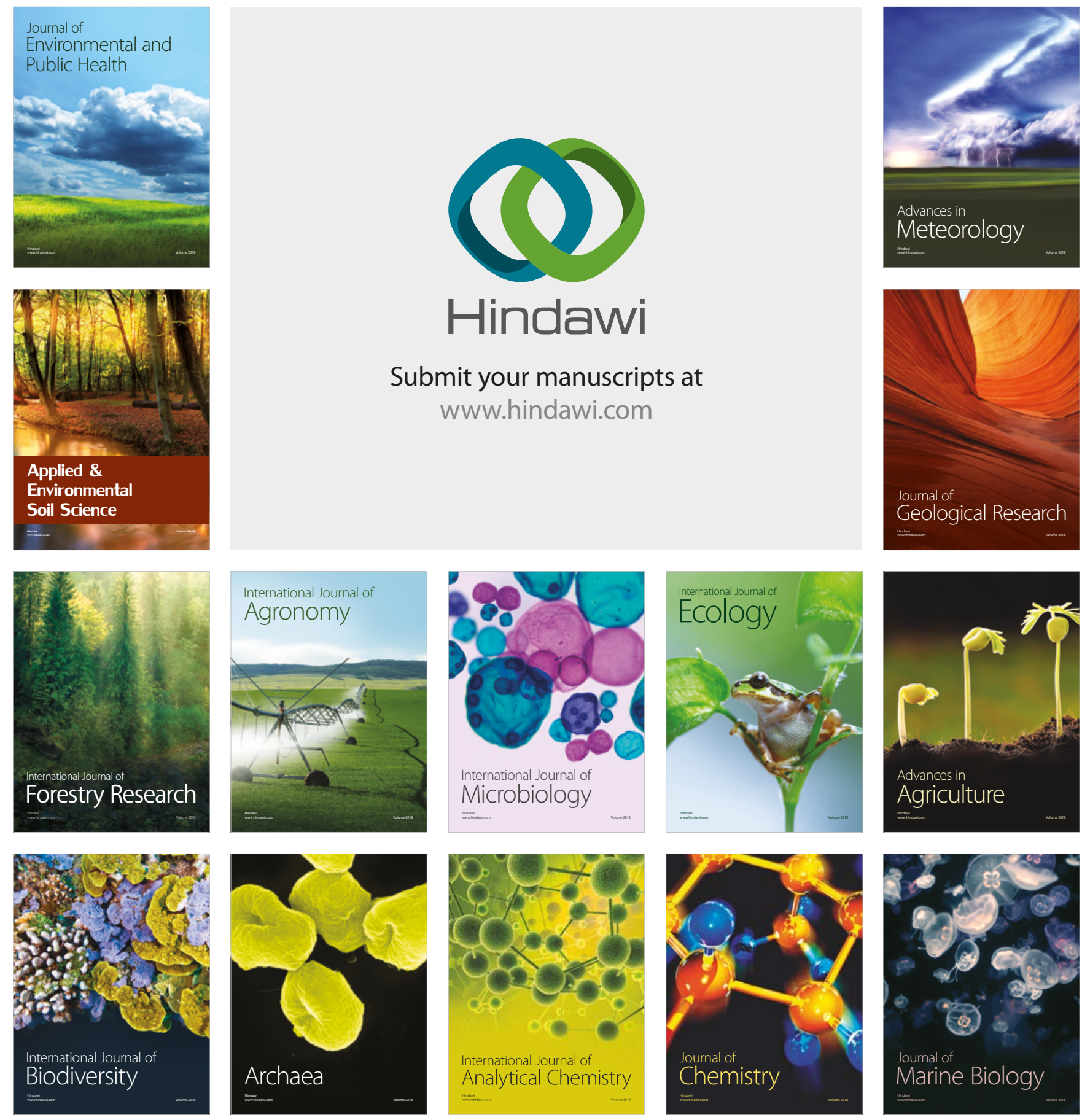